\title{
LA APLICACIÓN DE LA PRESCRIPCIÓN GRADUAL EN CASOS DE VIOLACIONES DE DERECHOS HUMANOS
}

\author{
Karinna Fernández Neira \\ karinnafn@gmail.com \\ Pietro Sferrazza Taibi \\ prietosferrazza@yahoo.es
}

\section{INTRODUCCIÓN}

En la jurisprudencia sobre derechos humanos dimanante de nuestra Corte Suprema, a lo largo de los años y, especialmente desde 1998 hasta la fecha, en virtud de un abanico de interesantes fallos, se han ido consolidando una serie de criterios esenciales que han permitido la aplicación de formas de autoexoneración tales como la amnistía y la prescripción. En algunos casos, la hermenéutica se ha enraizado en normas internas interpretadas con buen juicio y en otros, derechamente, se han utilizado argumentos propios del Derecho Internacional. Así, por ejemplo, la interpretación del secuestro como delito de ejecución permanente ha permitido impedir la aplicación de la amnistía e incluso de la prescripción, entendiéndose que el delito en cuestión no ha cesado de ser perpetrado, en base a la inexistencia de nuevos antecedentes o noticias de las víctimas. ${ }^{1}$ En otros casos, en cambio, tal como estábamos comentando, concebir las normas internacionales sobre imprescriptibilidad o prohibitivas de autoexoneración, relacionadas con crímenes de guerra o de lesa humanidad como constitutivas de ius cogens, ha permitido evitar la impunidad de algunos responsables. ${ }^{2}$

1 Cfr., a modo de ejemplo, sentencias de la Corte Suprema de 17.11.2004, causa rol № 517-04, por la desaparición de Miguel Ángel Sandoval Rodríguez y de 30.05.2006, rol № 3215-05, por el secuestro de Diana Frida A rón Svigilsky.

2 Cfr., a modo de ejemplo, sentencias de la Corte Suprema de 13.12.2006, rol N ${ }^{\circ} 559-04$, por los homicidios de Hugo Vásquez Martínez y M ario Superby Jeldres y de 18.01.2007, rol N²666-04, por el homicidio calificado de José Matías Ñanco. 
Sin embargo, en la jurisprudencia sobre derechos humanos del último bienio, se ha puesto en el centro de la discusión la posible aplicación de la prescripción gradual regulada en el artículo 103 del Código penal. ${ }^{3}$ Lo que ha hecho la Corte Suprema, so pretexto de "lo insensato que resulta una pena tan alta para hechos ocurridos largo tiempo atrás, pero que deben ser reprimidos, resultando de su reconocimiento una pena menor" "es utilizar la mencionada institución, que permite entender revestido el hecho de dos atenuantes muy calificadas, terminando por sancionar con penas bajas a los encausados y permitiendo, en la mayoría de los casos, la concesión de beneficios que impiden privarlos de libertad. ${ }^{5}$

Lo que trataremos de hacer en este estudio es analizar la jurisprudencia dictada a propósito de dicha institución en materia de derechos humanos y expresar una opinión crítica enfocando el problema desde diversas perspectivas.

\section{ANÁLISIS JURISPRUDENCIAL DE LA APLICACIÓN DE LA PRESCRIPCIÓN GRADUAL EN PROCESOS SOBRE DERECHOS HUMANOS}

Durante el transcurso del año 2007, la Corte Suprema, en concordancia con la más acreditada doctrina y jurisprudencia del sistema internacional de protección de los derechos humanos, reconoció en una serie de fallos vinculados a las violaciones de tales derechos, particularmente, casos de homicidios y secuestros, que dichos crímenes, en razón de su envergadura y especial carácter, son imprescriptibles e inamnistiables. Incluso, en reiteradas oportunidades, ha señalado que "la prohibición de autoexoneración que recae sobre los responsables de crímenes de lesa humanidad, no atañe sólo a situaciones tan obvias, como las amnistías autoconcedidas, sino que implica también una suspensión de la vigencia de instituciones preexistentes, como la prescripción de la acción penal, que fueron concebidas para operar en un estado de paz social al cual estaban llamados a servir, pero no en situaciones de vulneración de todas las instituciones sobre las cuales dicho Estado se erigía, y en beneficio precisamente de quienes provocaron dicho quebrantamiento", 6 agregando "que la evolu-

3 Artículo 103 del Código penal: "Si el responsable se presentare o fuere habido antes de completar el tiempo de la prescripción de la acción penal o de la pena, pero habiendo ya transcurrido la mitad del que se exige, en sus respectivos casos, para tales prescripciones, deberá el tribunal considerar el hecho como revestido de dos o más circunstancias atenuantes muy calificadas y de ninguna agravante y aplicar las reglas de los artículos 65, 66, 67 y 68 sea en la imposición de la pena, sea para disminuir la ya impuesta.

Esta regla no se aplica a las prescripciones de las faltas y especiales de corto tiempo".

4 S.C.S. de 30.07.2007, Rol: 3808-06, considerando $18^{\circ}$.

5 Para mayor claridad consultar cuadro anexo, adjuntado al final de este trabajo, el que precisa el número de fallos en los que la Corte Suprema ha aplicado la prescripción gradual, desde el 30 de julio del 2007 hasta fines de enero del 2009. En dicho cuadro, es posible observar los efectos de dicha concesión, en particular respecto del quantum de la pena, así como los consecuentes beneficios que se conceden a los responsables, de delitos de lesa humanidad.

6 S.C.S. de 13.03.2007, Rol: 3125-04, considerando 8‥ 
ción y progresividad del derecho internacional de los derechos humanos ya no autorizan al Estado a tomar decisiones cuya consecuencia sea la renuncia a la persecución penal de delitos de lesa humanidad, en pos de una convivencia social pacífica apoyada en el olvido de hechos que, por su entidad y significación para la comunidad humana, no dejan de ser vivenciados como gravísimos por el transcurso del tiempo ni por sus protagonistas ni por los afectados ni, en fin, por la sociedad toda".

Pese a estas afirmaciones, la Corte Suprema construyó una nueva línea jurisprudencial, iniciada con el pronunciamiento sobre la casación presentada en el caso seguido por el homicidio de Juan Luis Rivera Matus, ${ }^{8}$ fallo en el que concedió a los responsables, de oficio y en toda su extensión, el beneficio de la prescripción gradual, aseverando que si bien por su envergadura tales delitos no prescriben, es posible aplicar una atenuante muy calificada como el instituto penal reconocido en el artículo 103 del Código penal, fundando dicha concesión en "lo insensato que resulta una pena tan alta para hechos ocurridos largo tiempo atrás, pero que deben ser reprimidos, resultando de su reconocimiento una pena menor". ${ }^{9}$ El otorgamiento de este beneficio de carácter facultativo para los juzgadores, se traduce en una considerable disminución de la pena, que en la práctica permite a los condenados cumplirla en libertad.

Posteriormente, en procesos relacionados con desapariciones forzadas de personas, como los casos seguidos por el secuestro calificado de Ancacura M anquean, González Calculef, Hernández Hinostroza y Vega González, conocido como "Episodio Lago Ran$\mathrm{CO}^{110}$ y el secuestro calificado de Carlos Humberto Contreras M aluje, ${ }^{11}$ la Corte Suprema continuó concediendo este beneficio a los responsables, pero tratándose de investigaciones seguidas por secuestros utilizó un planteamiento diferente. En efecto, la propia Corte había señalado en el fallo pronunciado por secuestro de Diana A rón, que se trata de un delito de ejecución permanente, no siendo viable establecer una fecha de finalización de la consumación para los efectos de iniciar el cómputo de los plazos de prescripción. Así, para superar este importante argumento, en los casos ejemplificados nuestro máximo tribunal recalificó los hechos subsumiéndolos en el tipo de homicidio, con la sola finalidad de poder aplicar la prescripción gradual. Incluso en el caso seguido por el secuestro de Carlos Contreras Maluje, se consideró como prueba del homicidio y de la fecha de su ejecución, la declaración de muerte presunta de la víctima, confiriendo a esta última institución un efecto que excede los previstos por el legislador.

La mentada argumentación es ratificada con más fuerza por la Corte Suprema, en una fallo pronunciado el 27 diciembre del 2007, en un caso seguido por el secuestro calificado de 24 personas -entre ellas un menor de edad- conocido como "Episodio

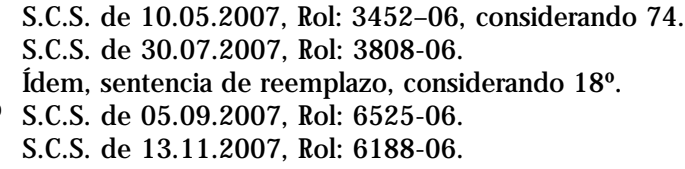


Parral". ${ }^{12}$ En este proceso la Corte Suprema, no obstante declarar que se trata de delitos de carácter imprescriptible por ser de consumación permanente,,$^{13}$ concede a los encausados el beneficio de la prescripción gradual sin ponderar la magnitud y gravedad de los delitos perpetrados, permitiendo a quienes ya habían sido condenados en primera y segunda instancia a penas que fluctuaban entre quince y diez años de presidio, la concesión de beneficios legales que impiden la privación de libertad.

Resulta pertinente observar dos aspectos en los que la Corte funda su línea argumental para la concesión de la prescripción gradual, que nunca habían sido esgrimidos con anterioridad. En primer lugar, para conceder este beneficio respecto de un delito de ejecución permanente, en abierta contradicción con lo dispuesto en el caso de Diana Arón, la Corte establece que la consumación del delito se ha producido al prolongarse el encierro o la detención por más de noventa días, iniciándose el cómputo de la media prescripción a partir de esta fecha, es decir, a contar del día noventa y dos ${ }^{14}$ justificando dicha afirmación en la idea de que superado este plazo la penalidad es siempre la misma, sin alteración de su desvalor, siendo este un argumento infundado y abiertamente contradictorio, toda vez que el parámetro temporal derivado de la expresión "más de 90 días" fue establecido por el legislador con la finalidad de calificar el tipo penal, lo que también ocurre con la calificante expresada en la frase "si de ello resultare un grave daño". A mbas exigencias se establecen para aumentar la sanción y no para atenuar la responsabilidad de los culpables. El segundo aspecto a mencionar, coincide con la justificación empleada por nuestro máximo tribunal para aplicar la prescripción gradual, consistente en anteriores aplicaciones de la institución en casos de homicidios cometidos en similares contextos, por lo que considera posible aplicarla en casos de secuestro, en los que el bien jurídico lesionado es de menor entidad. Nos remitimos a lo literal del fallo: "es menester tener en consideración expresa, que esta Corte, en relación con figuras de homicidio acaecidos en el mismo contexto de grave alteración o convulsión social, con motivo del 11 de septiembre de 1973, reconociendo la imprescriptibilidad de esta figura por ap licación de los tratados internacionales, ha aplicado como circunstancia de atenuación de la responsabilidad punitiva -no de extinción- la institución de la media prescripción [... ] lo que ha acaecido en relación con la afectación de un bien jurídico -la vida humana- de mayor enjundia que el sublite cual lo es el ejercicio de la libertad ambulatoria o de desplazamiento". ${ }^{15}$ Claramente estamos frente a un argumento de autoridad que desconoce abiertamente la envergadura del daño provocado a las víctimas, a sus familiares y a la

12 S.C.S. de 27.12.2007, Rol: 3587-05. Cabe hacer referencia al voto de prevención del ministro Sr. Rodríguez Espoz, quien no aceptó la prescripción gradual y estuvo por mantener las condenas de primera instancia; por su parte, el ministro Sr. Segura estimó que no resulta posible considerar las circunstancias temporales como fundamento para la aplicación de la media prescripción, en desprecio del reconocimiento de la prescripción plena; finalmente el ministro Ballesteros, pese a su opinión de absolver por prescripción de la acción penal, comparte el criterio de que a los encausados favorece la media prescripción como atenuante.

13 ídem, considerando $9^{\circ}$ en relación al $11^{\circ}$.

14 Ídem, cit., considerando 26 .

15 S.C.S de 27.12.2007, cit., considerando $27^{\circ}$. 
sociedad chilena, toda vez que no se trata de la sola privación de libertad de la víctimas, sino de su desaparición, lo que en el contexto internacional involucra, strictu sensu, la lesión de una triple identidad de bienes jurídicos: la libertad personal, la integridad física y la vida, de modo que este fallo está lejos de ser una respuesta adecuada, pertinente y proporcional a la comisión de delitos de lesa humanidad.

\section{DIVERSAS MANERAS DE ENFOCAR EL PROBLEMA DE LA APLICACIÓN DE LA PRESCRIPCIÓN GRADUAL}

Las críticas a la utilización de esta institución, pueden ser apreciadas desde una multiplicidad de perspectivas que esbozaremos a continuación.

\section{El transcurso del tiempo en} los delitos de lesa humanidad

Tal como lo consagra la Convención sobre la Imprescriptibilidad de los Crímenes de Guerra y de Lesa Humanidad, reconociendo un principio ya establecido por el ius cogens, los delitos de esa naturaleza, en razón de su gravedad y como consecuencia de haber ofendido a la humanidad en su conjunto, son imprescriptibles. Ese carácter ha sido reconocido en numerosos fallos de la Corte Suprema que, en consideración a los bienes jurídicos vulnerados vinculados a derechos internacionalmente garantizados, ha afirmado que el tiempo transcurrido no tiene efecto alguno en lo que se refiere a su persecución o castigo, lo que nos permite concluir que tampoco debería tener efecto en cuanto a la envergadura de la sanción.

A dicionalmente, debemos observar que nos encontramos frente a crímenes que tuvieron por objeto la desaparición de personas ejecutadas por un aparato estatal, con el objeto específico de provocar terror y no dejar huellas de su comisión. Por lo demás, cabe hacer presente que los responsables de tales crímenes, en la gran mayoría de los casos, siguen realizando conductas dirigidas a garantizar su impunidad merced la obstaculización de las investigaciones judiciales. De esa manera se impide a las víctimas y a la sociedad en su conjunto, acceder a la verdad, tanto respecto de las circunstancias que rodearon la comisión de los ilícitos como el destino final de las víctimas. Por ende, creemos que los responsables, hoy por hoy, no pueden obtener beneficios del tiempo que ellos mismos organizada y premeditadamente se han proveído, amparados en la ausencia de un perseguidor eficaz.

\section{La naturaleza jurídica de la prescripción gradual}

La prescripción gradual responde a la misma naturaleza jurídica que la prescripción, y se distingue de ella en los efectos jurídicos que produce, adicionalmente es de 
carácter facultativa en cuanto a su aplicación toda vez que se remite expresamente a las normas de determinación de las penas.

Este beneficio procede en aquellos casos en que "el inculpado se presentare o fuere habido antes de completar el tiempo de la prescripción de la acción penal o de la pena, pero habiendo ya transcurrido la mitad del que se exige, en sus respectivos casos, para tales prescripciones", permitiendo al juez "considerar el hecho como revestido de doso más circunstancias atenuantes muy calificadas y de ninguna agravante".

La Corte Suprema argumenta a favor de la aplicación de este beneficio en los crímenes cometidos durante la dictadura, afirmando que se trata de una institución independiente de la prescripción, cuyo fundamento radicaría en lo insensato de aplicar una pena alta a delitos cometidos hace tanto tiempo. Sin embargo, la doctrina, al referirse a esta institución, asevera que sus cimientos se encuentran en las mismas consideraciones de estabilización social y seguridad jurídica que dieron origen al artículo 93 del Código Penal, pero que está destinada a producir sus efectos en aquellos casos en que la realización de los fines previstos para la prescripción, no ocurren de forma espontánea, sino al cabo de un proceso gradual, ${ }^{16}$ es dicho proceso gradual, que en términos concretos significa que el tiempo necesario para prescribir está por cumplirse, el que justifica y fundamenta la atenuación de la pena, pero es evidente que se trata de un proceso que no experimentan los delitos de lesa humanidad, en razón de su carácter imprescriptible.

Así, la hipótesis fáctica necesaria para la aplicación de la prescripción gradual, requiere que se trate de un delito en vías de prescribir. Este es el fundamento de la atenuación de la responsabilidad penal. Sin embargo, ese fundamento pierde sentido en casos de delitos de lesa humanidad, ya que, como hemos sostenido en el punto anterior, se trata de delitos en que el transcurso del tiempo no produce efectos. La Corte Suprema ha aceptado en diversos fallos que, en consideración a la gravedad de estos crímenes y la aplicación de los tratados internacionales, el tiempo trascurrido desde su comisión no puede tomarse en cuenta para eximir de pena al encausado. Sin embargo, en otros casos, el tribunal no respeta el mismo criterio y aplica la media prescripción, otorgando efectos al transcurso del tiempo respecto de delitos que nunca prescribirán.

La Corte Suprema ha declarado que "trascurrido que fueran íntegramente los plazos establecidos para la prescripción de la acción penal derivada del ilícito, sin que la pueda declarar por impedirlo los convenios de Ginebra, no se divisa inconveniente para mitigar, como atenuante, la responsabilidad penal que le afecta al encausado". ${ }^{17}$ De esa manera incurre en una contracción ya que reconoce que la prescripción es una institución que los convenios internacionales impiden aplicar, pero le concede efectos a una institución que responde a sus mismos fundamentos y que tiene su misma naturaleza, esto es, la prescripción gradual, permitiendo la atenuación de la pena a tal grado que los responsables cumplen su condena en libertad.

\footnotetext{
16 J. Guzmán Dálbora, en Texto y comentarios del Código Penal chileno, Tomo I, Editorial Jurídica de Chile 2002, p. 483.

17 S.C.S. de 05.09.2007, cit., sentencia de reemplazo considerando $2 \stackrel{0}{ }$.
} 


\section{Obligaciones Internacionales Involucradas}

Existen numerosas obligaciones internacionales que se infringen cuando un poder del Estado de Chile opta por conceder beneficios de discutible aplicación en casos de crímenes de lesa humanidad. Estas obligaciones emanan de tratados internacionales en que Chile es Parte y que tienen por objeto proteger los derechos fundamentales de cierta categoría de actos ejecutados por los estados. En términos generales, el ordenamiento jurídico chileno, aplicado de buena fe y de acuerdo con los criterios hermenéuticos adecuados, reconoció la primacía del Derecho internacional sobre el Derecho interno cuando ratificó la Convención de Viena sobre el Derecho de los Tratados, lo que ocurrió antes de que la actual Constitución Política de 1980 entrara en vigencia. En consecuencia, en caso de conflictos normativos entre el Derecho interno y el Derecho internacional, Chile está obligado a hacer prevalecer las normas de este último. ${ }^{18}$

Los tratados internacionales forman parte de nuestro bloque de constitucionalidad, a partir de la remisión que de ellos efectúa el inciso final del artículo $5^{\circ}$ de nuestra Carta Fundamental, de cuya letra se desprende la preeminencia de aquellos. El referido inciso, en efecto, prescribe que "El ejercicio de la soberanía reconoce como limitación el respeto a los derechos esenciales que emanan de la naturaleza humana. Es deber de los órganos del Estado respetar y promover tales derechos, garantizados por esta Constitución, así como por los tratados internacionales ratificados por Chile y que se encuentren vigentes". Así, la norma en comento consolida la tesis de que los derechos esenciales de la persona humana configuran en el sistema jurídico chileno un sistema de doble fuente: una de carácter interno -la Constitución Política- y otra de carácter internacional que incorpora al ordenamiento jurídico chileno, a lo menos, los derechos contenidos en los tratados que el Estado libre, voluntaria y espontáneamente ha ratificado. Esto implica que el bloque de constitucionalidad está integrado por los derechos contenidos en los tratados y los consagrados en la propia Constitución Política. ${ }^{19}$

Relacionado a esto, respecto de los Convenios de Ginebra, la misma Corte Suprema ha afirmado que, en razón de su naturaleza y fines, tienen aplicación preeminente conforme lo dispuesto en el artículo 5o de la Carta Fundamental, de modo que no considerarlos u omitir su aplicación, importa un error de Derecho. Por lo tanto, el Derecho interno debe adecuarse a la normativa internacional que persigue garantizar los derechos esenciales que emanan de la naturaleza humana. ${ }^{20}$

En este sentido, el Pacto de Derechos Civiles y Políticos, en su art. $15 \mathrm{~N}^{\circ} 2$, prohíbe la impunidad de los responsables de crímenes de lesa humanidad, al señalar: "Nada de lo dispuesto en este artículo se opondráal juicio ni a la condena de una persona por actos u omisiones que, en el momento de cometerse, fueran delictivos según los

\footnotetext{
18 Peritaje de Humberto Nogueira Alcalá, en caso "La Última Tentación de Cristo" (Olmedo Bustos y otros), Sentencia 5 de febrero de 2001. Serie C No. 73, p. 13.

19 Ibídem, p. 14.

20 S.C.S., 09.09.1998, Rol 469-98, considerandos 9ㅇ y 10ㅇ․
} 
principios generales del derecho internacional reconocidos por la comunidad internacional". De tales principios generales del Derecho internacional, emana la obligación de perseguir y sancionar a los responsables de crímenes contra la humanidad, de modo que la obligación de sancionar estos delitos que recae sobre los Estados partes de la Comunidad Internacional, como el Estado de Chile, está por encima de la prescripción u otras instituciones extintivas de la responsabilidad penal.

Sin perjuicio de que dicha obligación surja a la vida del Derecho de entre los principios generales del Derecho internacional, cabe hacer presente que también está recogida en diversos cuerpos normativos; a saber: la Convención sobre la Imprescriptibilidad de los Crímenes de Guerra y de Lesa Humanidad y la Convención A mericana sobre Derechos Humanos. La primera, reconoce que la imprescriptibilidad de estos crímenes es un principio universal, aclarando, en su preámbulo, que su función es reconocer o declarar una regla de Derecho internacional ya existente que forma parte de aquellas normas imperativas que la comunidad internacional reconoce como no susceptibles de acuerdo en contrario, en conformidad a lo reconocido por la Convención de Viena sobre el Derecho de los tratados. La Corte Suprema ha sostenido que las prescripciones de esta Convención tienen rango de norma de ius cogens o principios generales del derecho internacional, a pesar de no haber sido ratificada por Chile. ${ }^{21}$ Finalmente, en concordancia con la más autorizada doctrina y jurisprudencia internacional, la misma Corte ha afirmado con absoluta claridad que las normas de Derecho internacional humanitario son parte integrante del ius cogens. Esto explica la obligatoriedad de las disposiciones humanitarias para los Estados, incluso si éstos no hayan aprobado los tratados respectivos, por cuanto la imperatividad de esta normativa no deriva del consentimiento de los Estados, sino de su carácter consuetudinario. ${ }^{22}$

El objeto de que la comunidad de las naciones declarara que los crímenes de lesa humanidad son imprescriptibles, tiene su fundamento en evitar que la sola prolongación en el tiempo de un régimen de terror termine por favorecer con la justicia de una garantía a quienes fueron pródigos en injusticia y violaciones de las garantías más preciadas de los pueblos bajo su dominio. ${ }^{23}$ Esta fundamentación de carácter internacional, evidentemente es aplicable a la institución de la media prescripción, ya que se trata de conceder beneficios previstos por el legislador para delitos de carácter distinto a los de lesa humanidad.

Conforme a lo establecido en el artículo 1.1 de la Convención Americana de Derechos Humanos, los Estados partes asumen dos obligaciones: respetar los derechos y libertades reconocidos en ella y garantizar su libre y pleno ejercicio. La obligación de garantizar consiste en una obligación de hacer, en particular, en organizar todo el

21 Cfr. Las sentencias de la Corte Suprema de 18.01.2007, Rol 2666-04, considerando 170 y de 13.03.2007, Rol 3125-04, considerando 13ㅇ.

22 S.C.S. de13.03.2007, cit., considerando 150.

23 Poltiof L., Sergio, Texto y Comentario del Código Penal Chileno, Tomo I, Editorial Jurídica de Chile, 2002, p. 464. 
aparato gubernamental de tal manera que sea capaz de asegurar jurídicamente el libre y pleno ejercicio de los derechos humanos. Para dar cumplimiento a esta obligación, la Corte Interamericana de Derechos Humanos ha establecido en numerosos fallos que los Estados deben prevenir, investigar y sancionar toda violación de derechos reconocidos por la Convención, con la consiguiente obligación de reparar los daños producidos a las víctimas de dichas violaciones. ${ }^{24}$

En el caso particular de Chile, la Corte Interamericana ha fallado expresamente que nuestro Estado no podrá argüir ninguna ley ni disposición de Derecho interno para eximirse de la orden de la Corte de investigar y sancionar penalmente a los responsables de crímenes de lesa humanidad. ${ }^{25}$

En relación a este punto debemos analizar cuáles son las características o requisitos que debe contener una sanción, con el objeto de cumplir con esta obligación internacional.

A. Fines de la pena en el sistema de protección de los derechos humanos. Ya hemos señalado que es clara y conocida la obligación que recae sobre los Estados partes de la comunidad internacional de sancionar a los responsables de delitos de lesa humanidad y que tal obligación tiene preeminencia sobre la prescripción u otras instituciones extintivas de la responsabilidad penal. A hora bien, la pena debe cumplir con los fines que le son propios y que fueron declarados por la A samblea General de las Naciones Unidas en su resolución 2583 (XXIV) de 15 de diciembre de 1969 en los términos siguientes: la sanción de los responsables por tales delitos "es un elemento importante para prevenir esos crímenes y proteger los derechos humanos y las libertades fundamentales, y para fomentar la confianza, estimular la cooperación entre pueblos y contribuir a la paz y la seguridad internacionales".

En este sentido, los ministros de la Corte Suprema, Sres. Cury y Rodríguez, confeccionaron un voto de minoría en el fallo pronunciado por la desaparición de Ricardo Rioseco Montoya y Luis Cotal Álvarez, ${ }^{26}$ en el que señalan que la autoexoneración establecida en los instrumentos internacionales respecto a estos delitos se refiere de manera primordial a las sanciones penales contempladas para ellas, pues es claro que respecto de hechos de esta clase, cobra una importancia fundamental la función de prevención general de las reacciones punitivas, la cual exige que las amenazas contenidas en las normas correspondientes se hagan efectivas en cualquier momento en que la persecución de los responsables se haga posible y aunque la de prevención especial parezca ya satisfecha porque el transcurso del tiempo haya convertido a los

24 Nash y Zalaquetr, "Proceso Penal y Derechos Humanos", en Revista de Derecho Procesal, actualizado en su jurisprudencia 2007, Santiago, 2004.

25 Corte IDH, caso A Imonacid A rellano, Sentencia 26 septiembre de 2006, serie C № 154, párrafos 152 y 153.

26 S.C.S de 04.08.05, Rol 457-05. 
infractores en ciudadanos inofensivos. La sociedad, en efecto, no toleraría que transgresiones de tal magnitud queden definitivamente impunes, con el pretexto de que el castigo ya no puede resocializar al que ya no está en condiciones de reincidir, pues, no obstante ello, sí puede actuar reforzando para el futuro en los ciudadanos el respeto por los valores elementales sobre los que descansa la posibilidad de una convivencia pacífica (prevención general positiva) y disuadiendo a quienes se sientan inclinados a incurrir en hechos semejantes (prevención general negativa).

Otra de las finalidades de la pena, cuando se trata de sancionar conductas que configuraron delitos de lesa humanidad, consiste en la reparación que implica para las víctimas y sus familiares una sanción adecuada a la gravedad del delito, en el entendido de que esta reparación además es una obligación del Estado y que surge tras cometerse una violación de una obligación internacional, pues una reparación integral no puede reducirse a la sola indemnización monetaria, lo que implicaría permitir a los Estados mantener la impunidad a cambio de dinero. Las víctimas requieren, por tanto, de una reparación integral que involucra, a lo menos, una investigación y revelación de los hechos constitutivos de la verdad y, por sobre todo, un esfuerzo por parte del Estado de castigar penal y disciplinariamente a quienes resultaren responsables. ${ }^{27}$

Recogiendo esta afirmación, la CIDH ha señalado: En consecuencia, el artículo 8.1 de la Convención A mericana, en conexión con el artículo 25.1 de la misma, confiere a los familiares de las víctimas el derecho a que la desaparición y muerte de estas últimas sean efectivamente investigadas por las autoridades del Estado; se siga un proceso contra los responsables de estos ilícitos; en su caso se les impongan las sanciones pertinentes, y se reparen los daños y perjuicios que dichos familiares han sufrido. ${ }^{28}$

B. Proporcionalidad de la pena. La obligación de los Estados de sancionar a los responsables de crímenes de lesa humanidad, se encuentra consagrada en el artículo 1.1 de la Convención Americana.

Al respecto la CIDH ha señalado que al ser el individuo y la humanidad las víctimas de todo crimen de lesa humanidad, los responsables de tales actos deben ser sancionados. A hora bien, lo que analizaremos en este punto es la magnitud necesaria de la sanción, para que pueda cumplir con los estándares internacionalmente pactados.

Que la sanción aplicable sea proporcional al crimen cometido, es un principio general consagrado en diversos cuerpos normativos de carácter internacional. A modo de ejemplo, podemos mencionar:

27 MénDEZ E., "Derecho a la verdad frente a las graves violaciones a los derechos humanos", en La aplicación de los tratados sobre derechos humanos por los tribunales locales, compiladores Martín A bregú y Christian Courtis, Centro de Estudios legales y Sociales, Editores del Puerto, Buenos Aires, 1997, pp. (517540) 525.

28 Corte IDH, caso Durand y Ugarte, Sentencia 28 de mayo de 1999, Serie C № 50 párrafo 130 y Corte IDH, caso Las Palmeras, Sentencia 4 de febrero de 2000, Serie C № 67, párrafo 65. 
- La Convención contra la Tortura y otros Tratos o Penas Crueles, Inhumanos o Degradantes. ${ }^{29}$

- Protocolo Facultativo de la Convención sobre los Derechos del Niño. ${ }^{30}$

- Convención sobre la Prevención y el Castigo de Delitos Contra Personas Internacionalmente Protegidas. ${ }^{31}$

- Convención Interamericana sobre Desaparición Forzada de Personas. ${ }^{32}$

De estos cuerpos normativos resulta claro concluir, que el orden jurídico debe responder racional y proporcionalmente a la gravedad de los hechos merced la selección de consecuencias previstas en los ordenamientos. No es admisible sancionar hechos gravísimos con penas levísimas, como sucede a través de procesos a "modo" o fraudulentos, rechazados por los órganos penales internacionales y también por la Corte Interamericana de Derechos Humanos. Tampoco sería admisible adoptar medidas de la mayor severidad cuando los hechos no revisten tan elevada gravedad. En ambas hipótesis se contrarían los principios de necesidad, racionalidad y proporcionalidad que gobiernan la previsión y aplicación de consecuencias jurídicas de las conductas ilícitas. ${ }^{33}$

En este sentido, la Comisión hizo ver la necesidad de que la Corte se refiera a la proporcionalidad de la sanción, en el caso conocido como la Masacre de la Rochela vs. Colombia, indicando que "es muy importante [...] que la Corte pueda fijar, como lo ha hecho en otros casos, principios orientadores del proceso de aplicación de ese marco legal en el ámbito interno del Estado", inter alia, "la existencia de un principio de proporcionalidad que no beneficie sólo al imputado, sino que constituya un derecho de la víctima de graves violaciones de derechos humanos". A simismo, la Comisión "destac[ó] la importancia" de que la Corte "ratifique el principio [...] de que en la investigación de graves violaciones a los derechos humanos sea imposible reconocer como compatible con la Convención A mericana la imposición de penas ínfimas o ilusorias, o que puedan significar una mera apariencia de justicia". ${ }^{34}$

La Corte Interamericana de Derechos Humanos ha afirmado que para que el Estado satisfaga el deber de garantizar adecuadamente los diversos derechos protegidos en la Convención, debe observar el principio de proporcionalidad de la pena. A este respecto, en particular, la Corte ha especificado esta obligación de la siguiente forma:

29 Art. 4.2: "Todo Estado Parte castigará esos delitos con penas adecuadas en las que se tenga en cuenta su gravedad".

30 Art. 3.3: "Todo Estado Parte castigará estos delitos con penas adecuadas a su gravedad".

31 Art. 2.2: "Cada Estado parte hará que esos delitos sean castigados con penas adecuadas que tengan en cuenta el carácter grave de los mismos".

32 Artículo III (primera parte): "Los Estados Partes se comprometen a adoptar, con arreglo a sus procedimientos constitucionales, las medidas legislativas que fueren necesarias para tipificar como delito la desaparición forzada de personas, y a imponerle una pena apropiada que tenga en cuenta su extrema gravedad. Dicho delito será considerado como continuado o permanente mientras no se establezca el destino o paradero de la víctima".

33 Voto razonado del juez Sergio García Ramírez a la sentencia de la Corte IDH, caso Goiburú, Sentencia 22 de septiembre de 2006. Serie C № 153, párrafo 7.

34 Corte IDH, caso de la Masacre de la Rochela, Sentencia 11 de mayo de 2007, Serie C № 163, párrafo 191. 
"En cuanto al referido principio de proporcionalidad de la pena, la Corte estima oportuno resaltar que la respuesta que el Estado atribuye a la conducta ilícita del autor de la transgresión debe ser proporcional al bien jurídico afectado y a la culpabilidad con la que actuó el autor, por lo que se debe establecer en función de la diversa naturaleza y gravedad de los hechos". 35

Respecto al principio de benignidad de una ley anterior, como en el caso de la institución de la prescripción gradual, la Corte Interamericana señala que debe procurarse su armonización con el principio de proporcionalidad, de manera que no se haga ilusoria la justicia penal. Todos los elementos que incidan en la efectividad de la pena deben responder a un objetivo claramente verificable y ser compatibles con la Convención. ${ }^{36}$ En este sentido, la Corte Suprema ha afirmado que de los Convenios de Ginebra, surge para Chile la obligación de tomar todas las medidas legislativas necesarias en orden a fijar las adecuadas sanciones penales que hayan de aplicarse a las personas que cometen, o den orden de cometer, cualquiera de las contravenciones graves definidas en el Convenio. ${ }^{37}$

C. La pertinencia de la pena. Pertinencia es el estándar exigido por el sistema de protección internacional de derechos humanos a las sanciones que se impongan a los responsables de crímenes de lesa humanidad. Ello significa que la envergadura del castigo debe servir, en la práctica, para cumplir con los fines que ya hemos especificado y con la proporcionalidad necesaria. A dicionalmente, la Comisión y la Corte Interamericana asocian a la obligación contenida en el 1.1. de la Convención este estándar.

A modo de ejemplo, en relación al artículo 1.1 de la Convención, la Comisión ha sostenido que de conformidad a las reglas del Derecho internacional y la jurisprudencia de la Corte, la acción u omisión de cualquier autoridad pública compromete la responsabilidad del Estado respecto de los artículos de la Convención y éste está en la obligación de identificar a los responsables de tales acciones u omisiones e imponerles las sanciones pertinentes. ${ }^{38}$ Del mismo modo, en diversos informes ha precisado que las sanciones pertinentes son las adecuadas según la gravedad de las violaciones. ${ }^{39}$

Por su parte, en diversos fallos la Corte ha señalado que el Estado tiene el deber jurídico de prevenir razonablemente las violaciones de los derechos humanos, de investigar seriamente, con los medios a su alcance, las violaciones que se hayan cometido dentro del ámbito de su jurisdicción a fin de identificar a los responsables, de imponerles las sanciones pertinentes y de asegurar a la víctima una adecuada repara-

\footnotetext{
Ibídem, Párr. 196.

Ibídem, Párr. 196.

S.C.S. 10.05.2007, Rol 3452-06, considerandos 39 y 40.

38 Corte IDH, caso del Tribunal Constitucional, Sentencia 31 de enero de 2001. Serie C № 71 párr. 105 letra a).

39 Informe № 23/01, del 5 marzo de 2002.
} 
ción..$^{40}$ Específicamente, con respecto a las violaciones cometidas por el Perú y sin desconocer los esfuerzos de este Estado por establecer la "verdad histórica", indicó que en el marco de los artículos 1.1, 8 y 25 de la Convención, los familiares de las víctimas tienen el derecho y los Estados la obligación, a que lo sucedido a aquéllas sea efectivamente investigado por las autoridades del Estado, se siga un proceso contra todos los presuntos responsables de estos ilícitos y, en su caso, se les impongan las sanciones pertinentes. ${ }^{41}$

\section{CONCLUSIONES}

Estos crímenes, en razón de su gravedad y de sus perniciosas consecuencias, no se han cometido hace un tiempo determinado sino que continúan cometiéndose. En estos casos, es necesario y pertinente ponderar a la hora de establecer la sanción el carácter permanente de su comisión, la extensión del mal causado, la gravedad de las consecuencias, todo lo cual nos permite señalar que estos crímenes se encuentran más allá de lo tolerable, lo que permite exigir su castigo en forma actual y permanente. Adicionalmente, el que los responsables de tan graves crímenes se les conceda la libertad no obstante ser declarados culpables de su consumación, provoca un nuevo daño a los familiares de las víctimas, quienes observan como los responsables de la desaparición o muerte de sus familiares, gozan de una impunidad pues en la práctica no enfrentan una sanción efectiva, lo que provoca finalmente un cuestionamiento de la eficacia de nuestro ius puniendi, cuando se trata de juzgar a los responsables de crímenes de lesa humanidad. En particular, cuando nos encontramos en un país que juzga, investiga y sanciona crímenes de lesa humanidad como la desaparición forzada y la ejecución sumaria de personas, con el estatuto legislativo de los delitos comunes. Tal razonamiento hace imposible aplicar esta medida a los responsables de dichos crímenes.

Los Convenios Internacionales impiden aplicar instituciones como la prescripción y la amnistía, pues su aplicación involucra impunidad, pero la impunidad sin lugar a duda también la encontramos cuando responsables de crímenes de esta envergadura cumplen su sanción en libertad, gracias al tiempo transcurrido desde la comisión de los mismos, lo que se traduce en que la respuesta que el Estado de Chile está otorgando a la comisión de estos crímenes es en esencia errónea e importa una infracción de las obligaciones internacionales, al buscar sancionar con penas ficticias a los responsables de dichos crímenes; la única forma de que la finalidad perseguida por la penalidad de estos crímenes, que no es otra que "el nunca más" se cumpla, consiste en que la pena se adecue a la proporcionalidad del crimen cometido. Y si esta afirmación fuera recogida por nuestros tribunales, permitiría la sanción pertinente de los responsables, sin que se les concedan beneficios inadecuados, que terminan convirtiendo la condena en un fraude de etiqueta que implica la impunidad de los responsables.

40 Corte IDH, caso Velásquez Rodríguez, Sentencia 26 de junio de 1987, Serie C № 1, párrafo 174 y caso Godínez Cruz, Sentencia 26 de junio de 1987, Serie C № 3, párrafo 184.

41 CIDH, caso La Cantuta, Sentencia 29 de noviembre de 2006, Serie C № 162, párrafo 224. 
CUADRO ANEXO:

Fallos pronunciados por la Excelentísima Corte Suprema, en causas relacionadas con delitos de lesa humanidad. Entre el 30 de julio del año 2007 y enero de $2009^{42}$

\begin{tabular}{|c|c|c|c|c|c|c|c|c|}
\hline$\frac{1}{2}$ & $\begin{array}{l}\text { NOMBRE } \\
\text { EISODIO } \\
\text { Rol Corte } \\
\text { Suprema } \\
\text { Fecha de la } \\
\text { Sentencia }\end{array}$ & $\begin{array}{l}\text { Número } \\
\text { de } \\
\text { Víctimas }\end{array}$ & $\begin{array}{l}\text { Nombre y } \\
\text { Grado del } \\
\text { Agente }\end{array}$ & $\begin{array}{l}\text { Tipo } \\
\text { penal }\end{array}$ & $\begin{array}{l}\text { Participa- } \\
\text { ción del } \\
\text { Agente }\end{array}$ & $\begin{array}{c}\text { Decisión y } \\
\text { circunstancias } \\
\text { modificatorias de la } \\
\text { responsabilidad penal }\end{array}$ & Pena & $\begin{array}{l}\text { Concesión de beneficios } \\
\text { altemativos a la pena } \\
\text { privativa de libertad }\end{array}$ \\
\hline 5 & $\begin{array}{l}\text { Ejecución de } \\
\text { Juan Luis } \\
\text { Rivera Matus } \\
3808-2006 \\
30 \text { julio } 2007\end{array}$ & 1 & $\begin{array}{l}\text { Freddy Enrique } \\
\text { Ruiz Bunger, } \\
\text { General en } \\
\text { retiro de la } \\
\text { FACH }\end{array}$ & $\begin{array}{l}\text { Homicidio } \\
\text { calificado }\end{array}$ & Encubridor & $\begin{array}{l}\text { Sentencia } \\
\text { Condenatoria } \\
\text { Atenuante de irreprochable } \\
\text { conducta anterior (Art. } 11 \\
\text { № } 6 \text { CP) } \\
\text { Prescripción gradual (Art. } \\
\text { 103 CP) }\end{array}$ & $\begin{array}{l}\text { Condenado a la pena de tres años y } \\
\text { un día de presidio menor en su grat } \\
\text { do medio más accesorias legales. }\end{array}$ & $\begin{array}{l}\text { Remisión condicional de la } \\
\text { pena. }\end{array}$ \\
\hline N & & & $\begin{array}{l}\text { Carlos Arturo } \\
\text { Madrid Hayden } \\
\text { Coronel en } \\
\text { retiro de la } \\
\text { FACH }\end{array}$ & $\begin{array}{l}\text { Homicidio } \\
\text { calificado }\end{array}$ & Encubridor & $\begin{array}{l}\text { Sentencia Condenatoria } \\
\text { Atenuante de irreprochable } \\
\text { conducta anterior (Art. } 11 \text { № } \\
6 \text { CP) } \\
\text { Prescripción gradual (Art. } \\
\mathbf{1 0 3 ~ C P ) ~}\end{array}$ & $\begin{array}{l}\text { Condenado a la pena de tres años y } \\
\text { un día de presidio menor en su gra- } \\
\text { do medio más accesorias legales. }\end{array}$ & $\begin{array}{l}\text { Remisión condicional de la } \\
\text { pena. }\end{array}$ \\
\hline & & & $\begin{array}{l}\text { Álvaro Julio } \\
\text { Federico } \\
\text { Corbalán } \\
\text { Castilla } \\
\text { Mayor en retiro } \\
\text { del ejército }\end{array}$ & $\begin{array}{l}\text { Homicidio } \\
\text { calificado }\end{array}$ & Autor & $\begin{array}{l}\text { Sentencia Condenatoria } \\
\text { Atenuante de irreprochable } \\
\text { conducta anterior } \\
\text { (Art. } 11 \text { № } 6 \text { CP) } \\
\text { Prescripción gradual } \\
\text { (Art 103 CP) }\end{array}$ & $\begin{array}{l}\text { Condenados a la pena de cuatro } \\
\text { años de presidio menor en su gra- } \\
\text { do máximo más las accesorias le- } \\
\text { gales. }\end{array}$ & $\begin{array}{l}\text { No se concede por haber sido } \\
\text { condenado a presidio perpe- } \\
\text { tuo por la participación que } \\
\text { le correspondió en calidad de } \\
\text { autor del delito de homicidio } \\
\text { calificado de Juan Alegría } \\
\text { Mundaca. }\end{array}$ \\
\hline
\end{tabular}

42 Cuadro elaborado por los autores en base a los fallos pronunciados por la Excelentísima Corte Suprema, y a información proporcionada por el Programa Continuación Ley 19.123 del Ministerio del Interior. Se inicia el estudio con la sentencia pronunciada a consecuencia de ilícitos perpetrados en contra de Juan Luis Rivera Matus el 30.07.07, por ser el primer fallo en que se aplica la institución de la prescripción gradual, desde que la Corte Suprema reconociera el carácter de imprescriptibles de los delitos de lesa humanidad, en conformidad a las normas del ius cogens, período jurisprudencial que se inicia con la sentencia de la Corte Suprema de 13.12.2006, rol N 559-04, por los homicidios de Hugo Vásquez Martínez y Mario Superby Jeldres. 


\begin{tabular}{|c|c|c|c|c|c|}
\hline 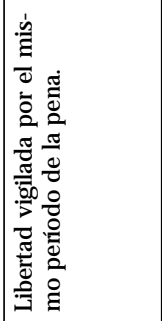 & & & & & \\
\hline 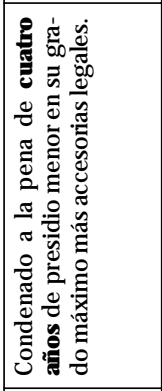 & 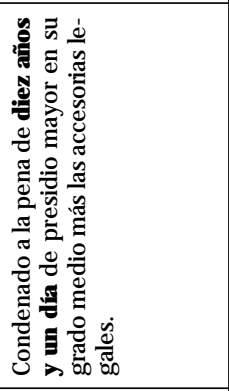 & 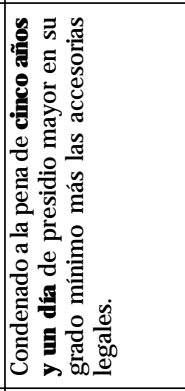 & 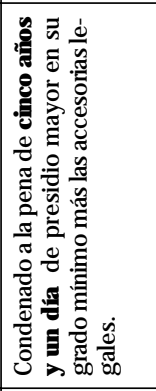 & 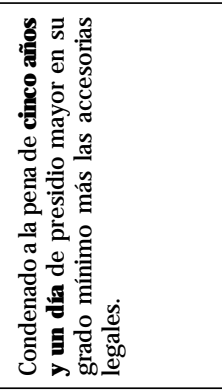 & 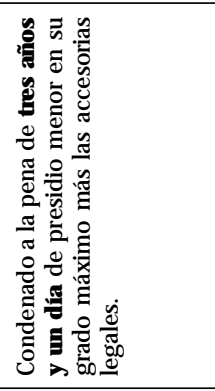 \\
\hline 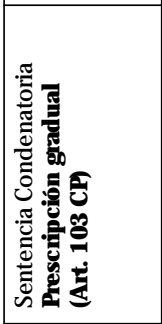 & 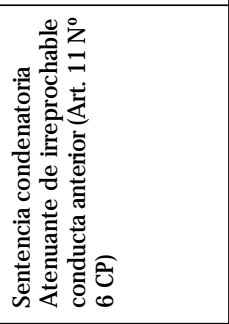 & 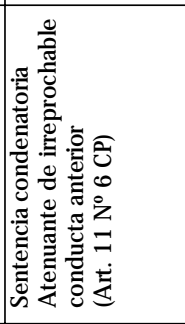 & 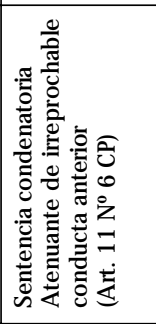 & 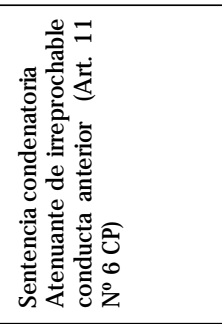 & 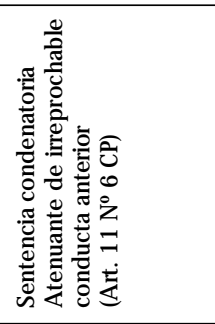 \\
\hline 高 & 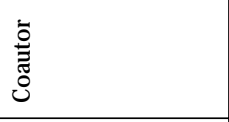 & 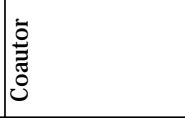 & 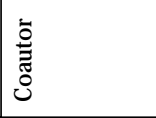 & 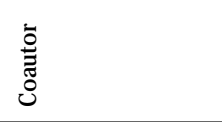 & 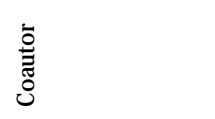 \\
\hline 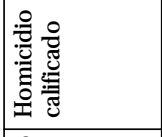 & 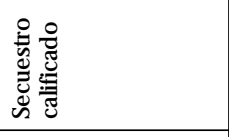 & 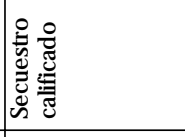 & 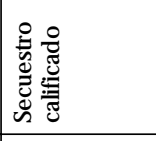 & 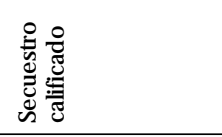 & 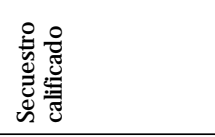 \\
\hline 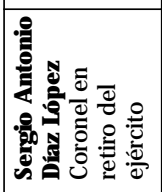 & 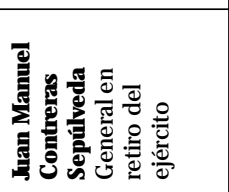 & 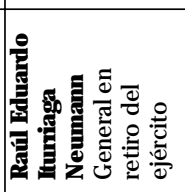 & 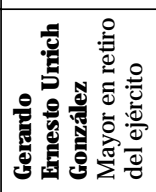 & 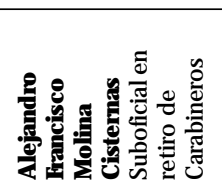 & 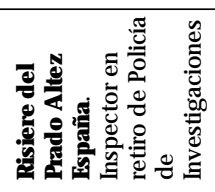 \\
\hline & $N$ & & & & \\
\hline & 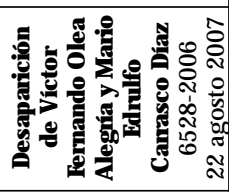 & & & & \\
\hline
\end{tabular}


Karinna Fernández Neira • Pietro Sferrazza Taibi

\begin{tabular}{|c|c|c|c|c|c|c|c|}
\hline & 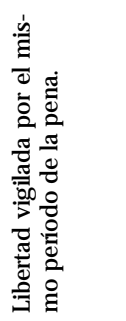 & 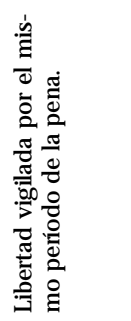 & 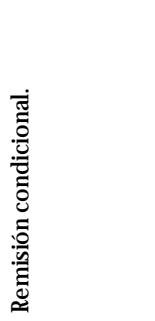 & 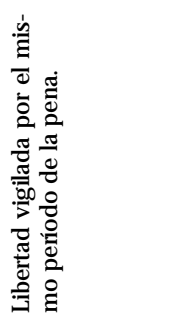 & 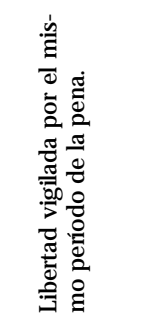 & 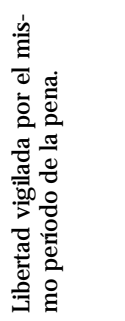 & \\
\hline 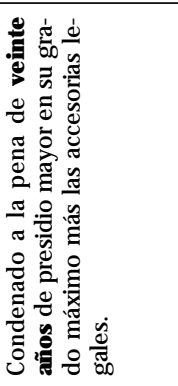 & 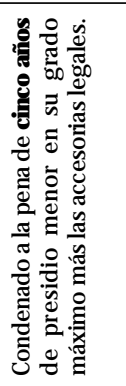 & 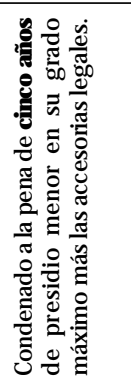 & 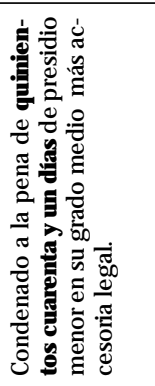 & 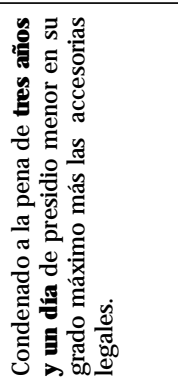 & 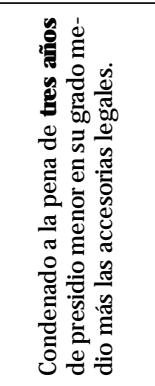 & 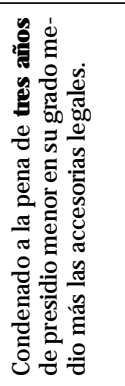 & 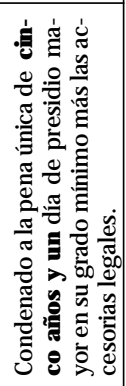 \\
\hline 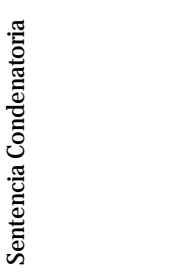 & 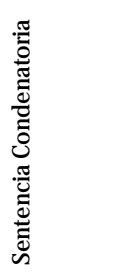 & 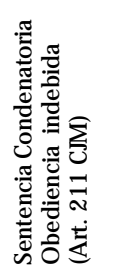 & 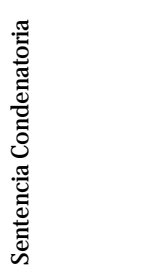 & 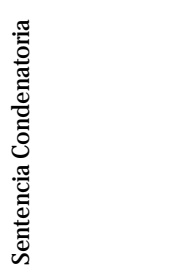 & 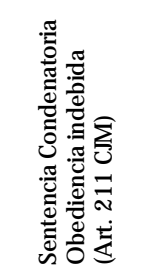 & 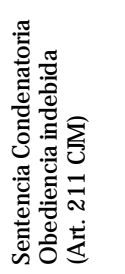 & 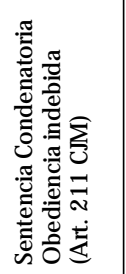 \\
\hline 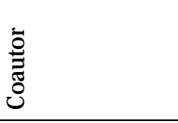 & 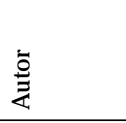 & $\begin{array}{l}\grave{\grave{a}} \\
\stackrel{5}{4}\end{array}$ & $\frac{\mathscr{\varrho}}{\frac{0}{0}}$ & $\begin{array}{l}\grave{0} \\
\stackrel{3}{4}\end{array}$ & 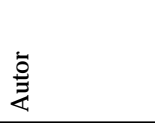 & 产 & 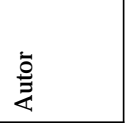 \\
\hline 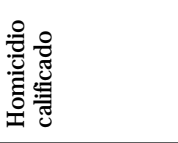 & 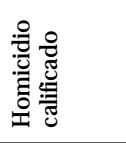 & 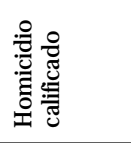 & & 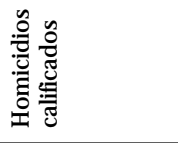 & 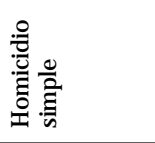 & 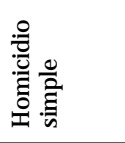 & 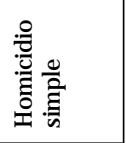 \\
\hline 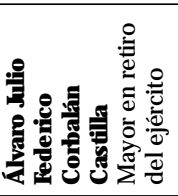 & 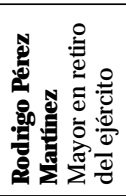 & 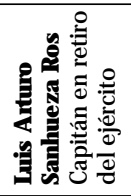 & 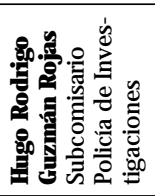 & 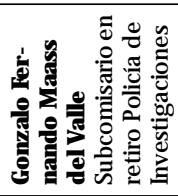 & 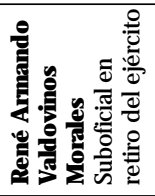 & 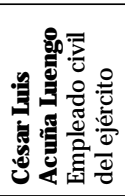 & 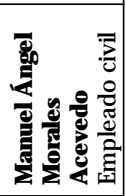 \\
\hline $\mathcal{F}$ & & & & & & & \\
\hline 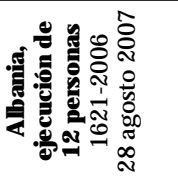 & & & & & & & \\
\hline
\end{tabular}




\begin{tabular}{|c|c|c|c|c|c|c|}
\hline & & 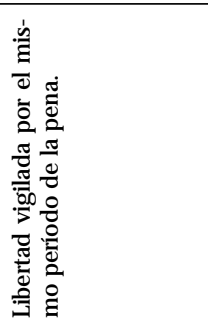 & 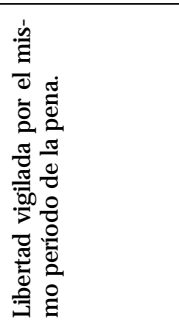 & 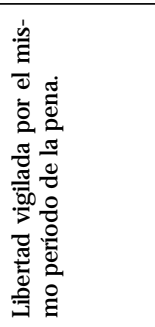 & 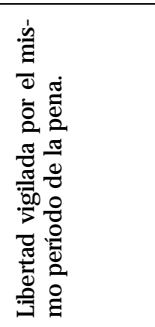 & \\
\hline & 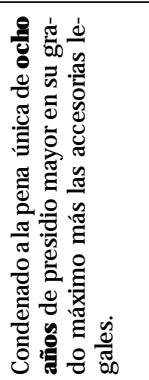 & 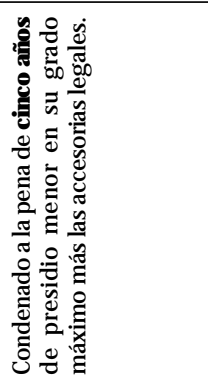 & 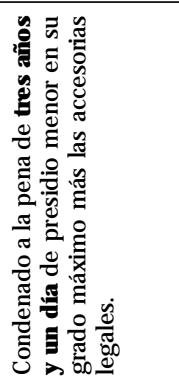 & 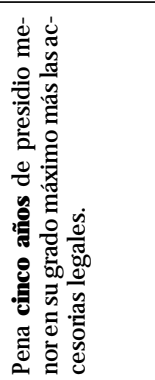 & 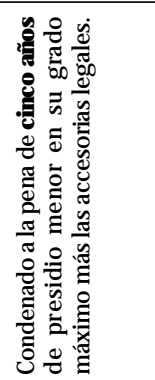 & 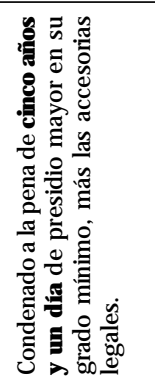 \\
\hline & 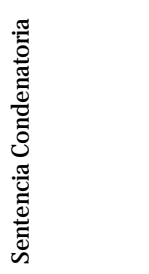 & 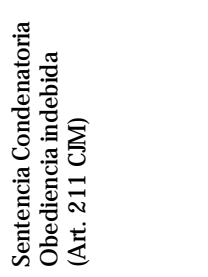 & 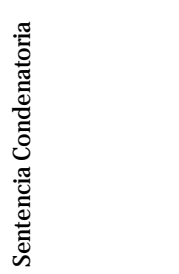 & 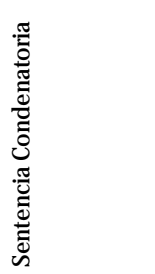 & 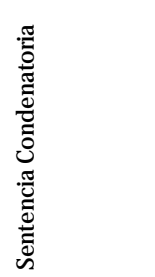 & 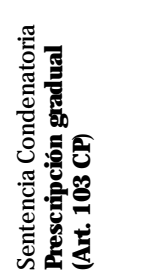 \\
\hline & $\frac{\grave{2}}{3}$ & 产 & $\begin{array}{l}\frac{1}{0} \\
\frac{3}{<}\end{array}$ & 产 & ⿳亠口冋 & ষ⿳亠口冋 \\
\hline & 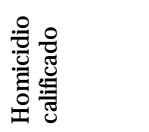 & 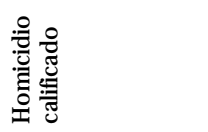 & 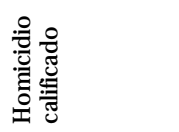 & 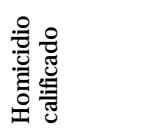 & 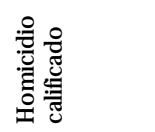 & 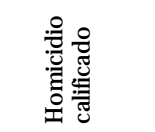 \\
\hline 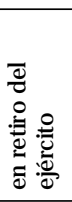 & 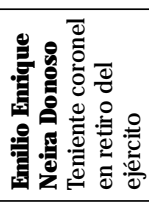 & 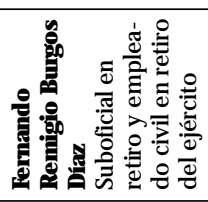 & 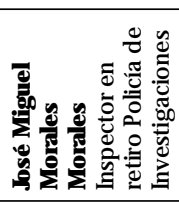 & 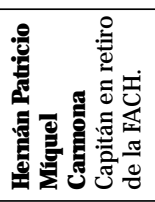 & 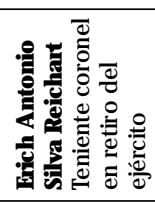 & 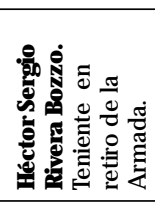 \\
\hline & & & & & & $\nabla$ \\
\hline & & & & & & 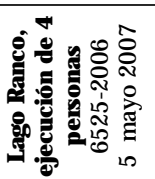 \\
\hline
\end{tabular}


Karinna Fernández Neira • Pietro Sferrazza Taibi

\begin{tabular}{|c|c|c|c|c|c|}
\hline 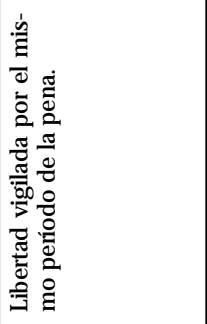 & 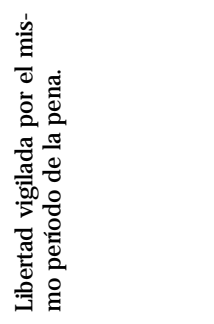 & 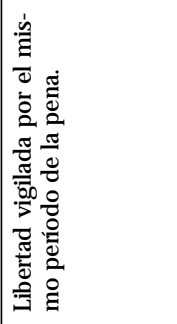 & 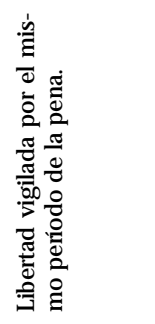 & & \\
\hline 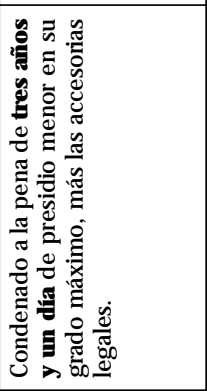 & 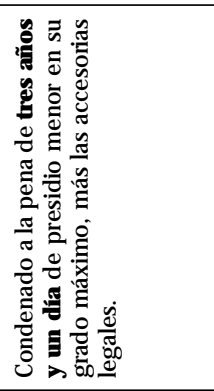 & 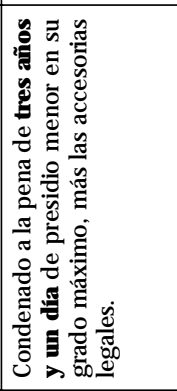 & 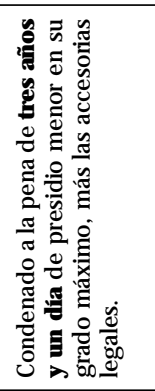 & 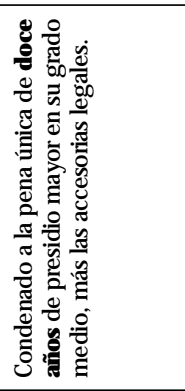 & $\begin{array}{l}\frac{8}{0} \\
\frac{0}{10} \\
\frac{8}{4}\end{array}$ \\
\hline 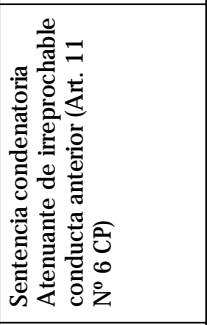 & 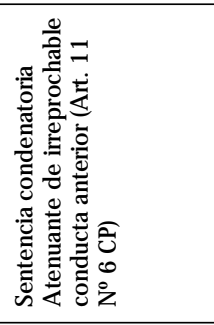 & 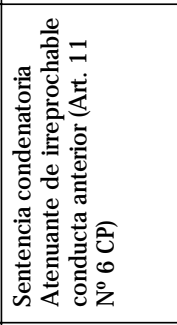 & 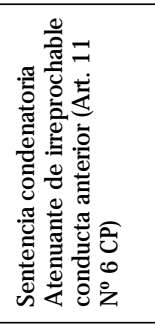 & 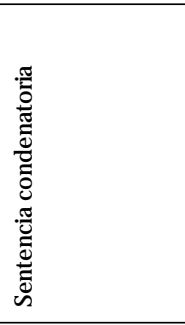 & 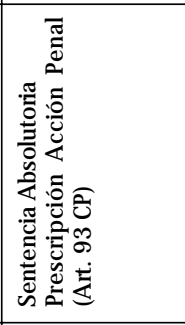 \\
\hline 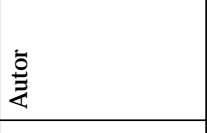 & $\frac{\grave{a}}{\frac{3}{4}}$ & $\begin{array}{l}\grave{0} \\
\text { 妾 } \\
\end{array}$ & 高 & 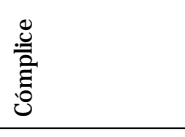 & $\begin{array}{l} \\
\frac{9}{4} \\
\end{array}$ \\
\hline 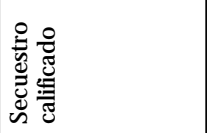 & 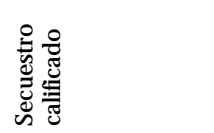 & 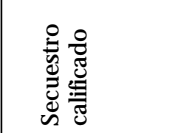 & 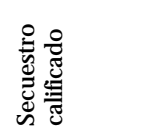 & 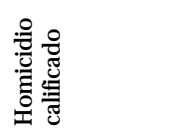 & 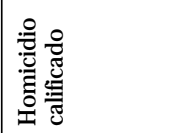 \\
\hline 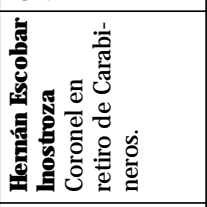 & 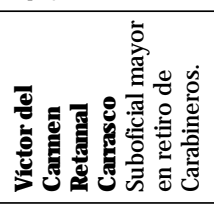 & 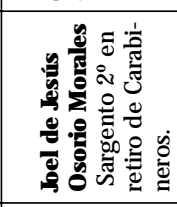 & 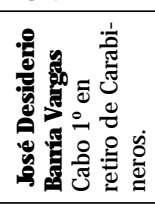 & 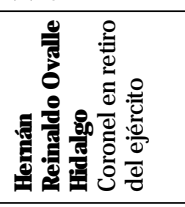 & 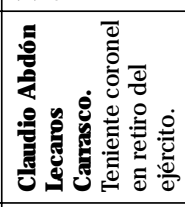 \\
\hline$r$ & & & & $m$ & $m$ \\
\hline 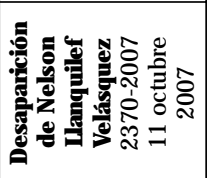 & & & & 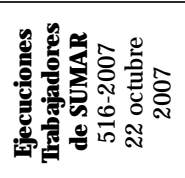 & 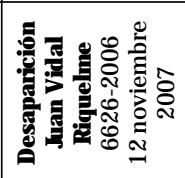 \\
\hline
\end{tabular}




\begin{tabular}{|c|c|c|c|c|c|c|}
\hline 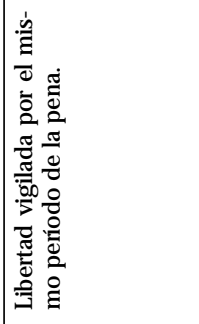 & 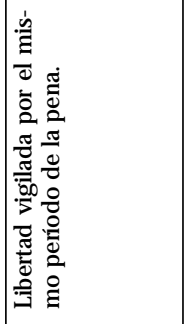 & 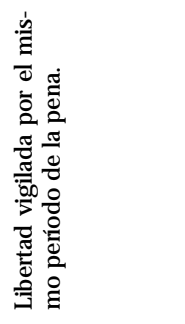 & & 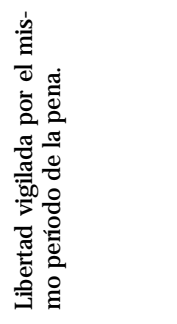 & & \\
\hline 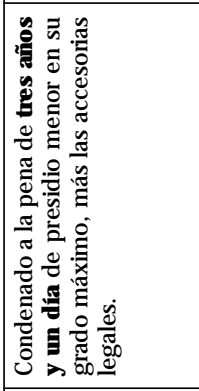 & 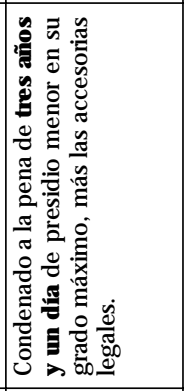 & 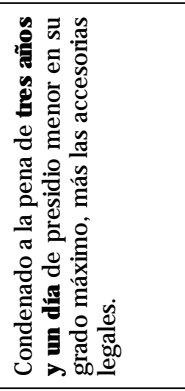 & 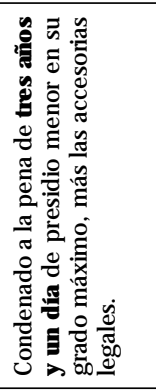 & 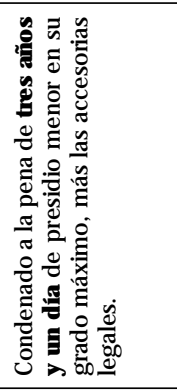 & 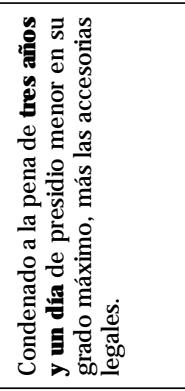 & 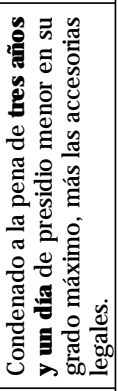 \\
\hline 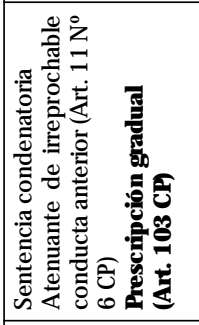 & 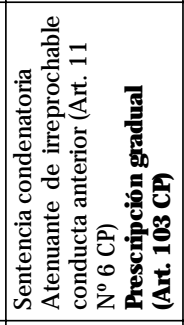 & 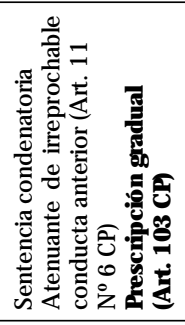 & 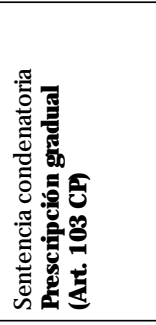 & 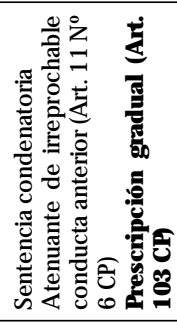 & 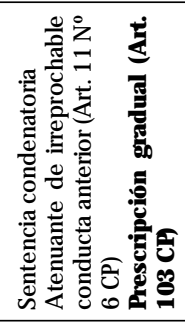 & 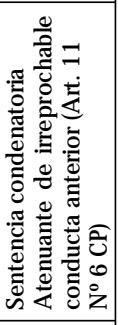 \\
\hline 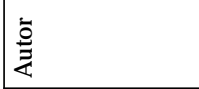 & \begin{tabular}{|l} 
\\
$\frac{9}{\alpha}$ \\
\end{tabular} & $\frac{\grave{g}}{\frac{9}{\alpha}}$ & $\frac{\grave{g}}{\frac{1}{\alpha}}$ & $\frac{\grave{o}}{\frac{1}{\alpha}}$ & 高 & $\frac{\grave{9}}{\overleftarrow{4}}$ \\
\hline 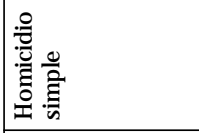 & 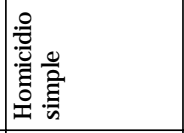 & 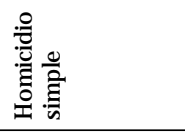 & 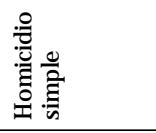 & 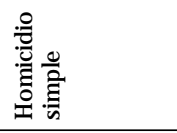 & 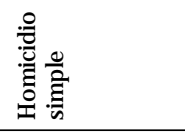 & 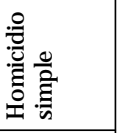 \\
\hline 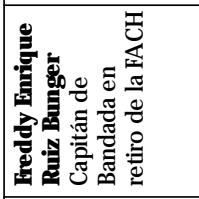 & 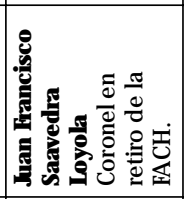 & 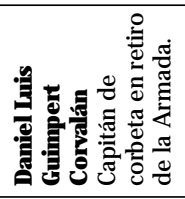 & 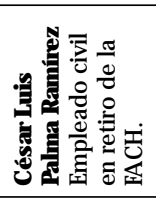 & 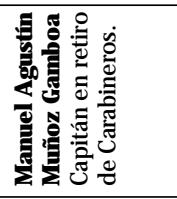 & 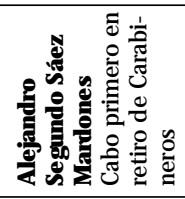 & 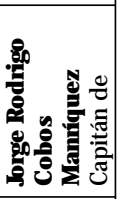 \\
\hline$\tau$ & & & & & & \\
\hline 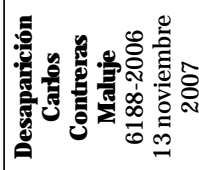 & & & & & & \\
\hline
\end{tabular}




\begin{tabular}{|c|c|c|c|c|c|c|}
\hline & 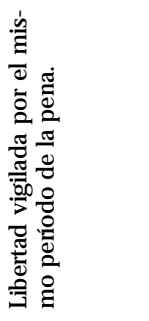 & 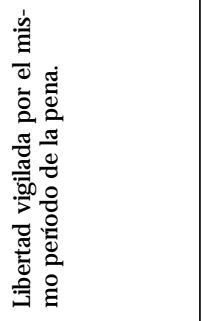 & 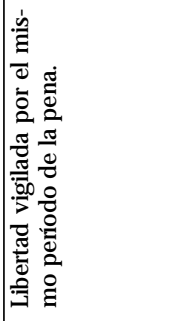 & & & \\
\hline & 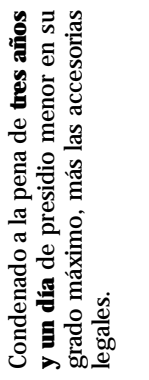 & 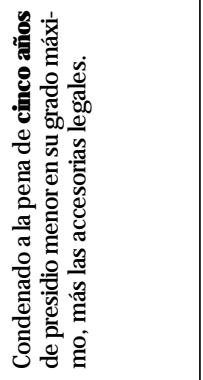 & 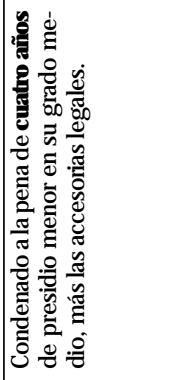 & 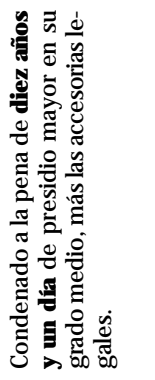 & $\begin{array}{l}\frac{8}{9} \\
\frac{0}{4} \\
\frac{0}{4}\end{array}$ & $\begin{array}{l}\frac{8}{0} \\
\frac{10}{4} \\
\frac{0}{4}\end{array}$ \\
\hline \multirow[t]{3}{*}{ 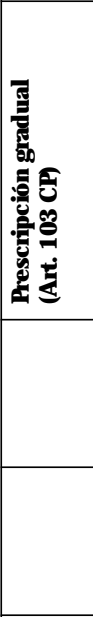 } & 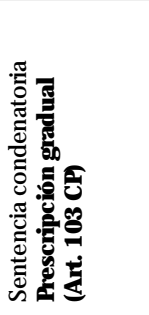 & 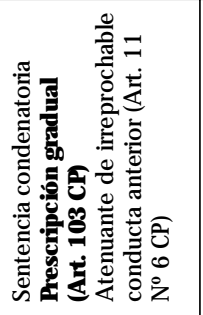 & 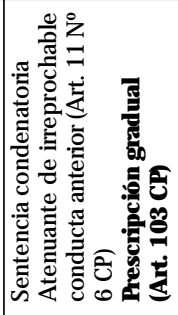 & 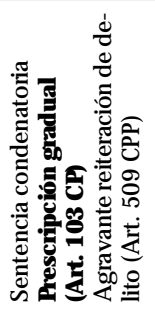 & 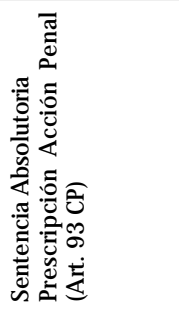 & 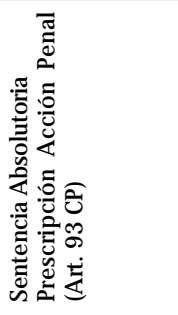 \\
\hline & 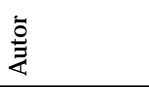 & 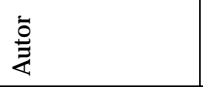 & 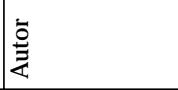 & 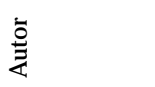 & 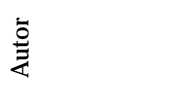 & $\begin{array}{l}\grave{0} \\
\stackrel{0}{3}\end{array}$ \\
\hline & 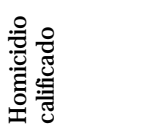 & 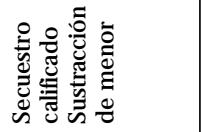 & 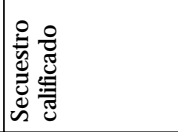 & 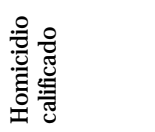 & 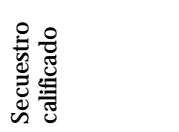 & 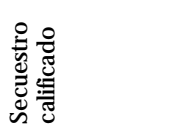 \\
\hline \multirow[t]{3}{*}{ 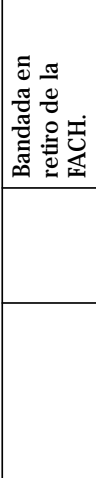 } & 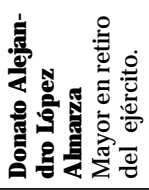 & 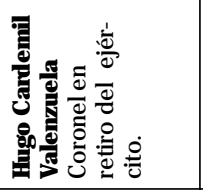 & 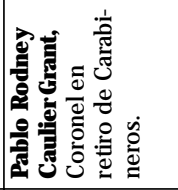 & 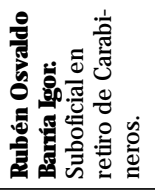 & 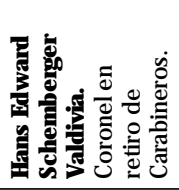 & 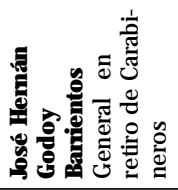 \\
\hline & $r$ & $\hat{N}$ & & $\wedge$ & $N$ & \\
\hline & 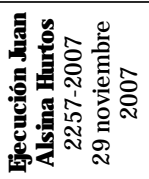 & 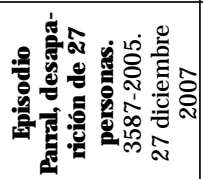 & & 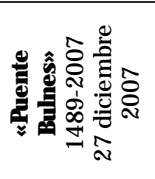 & 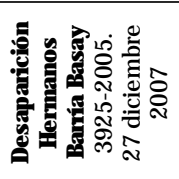 & \\
\hline
\end{tabular}




\begin{tabular}{|c|c|c|c|c|c|c|c|c|}
\hline & & & & & 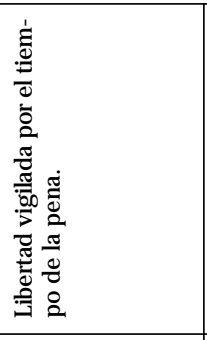 & 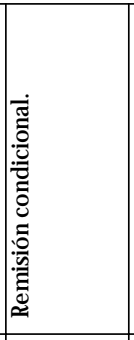 & & 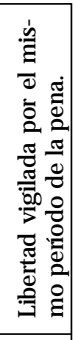 \\
\hline $\begin{array}{l}\frac{8}{0} \\
\frac{0}{4} \\
\frac{9}{4}\end{array}$ & $\begin{array}{l}\frac{8}{0} \\
\frac{0}{0} \\
\frac{0}{4}\end{array}$ & $\begin{array}{l}\frac{8}{9} \\
\frac{9}{0} \\
\frac{0}{4}\end{array}$ & $\begin{array}{l}\frac{8}{8} \\
\frac{0}{6} \\
\frac{0}{4}\end{array}$ & $\begin{array}{l}\frac{8}{9} \\
\frac{9}{03} \\
\frac{8}{4}\end{array}$ & 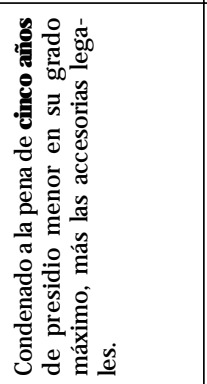 & 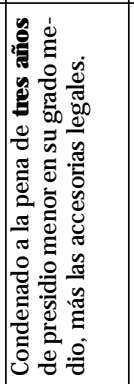 & $\begin{array}{l}\frac{8}{9} \\
\frac{0}{0} \\
\frac{0}{4}\end{array}$ & 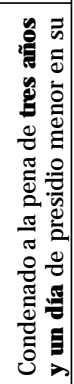 \\
\hline 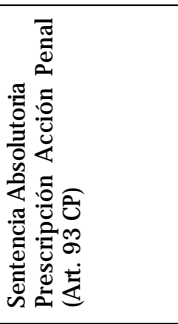 & 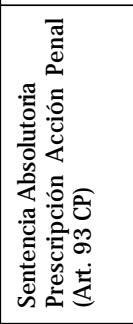 & 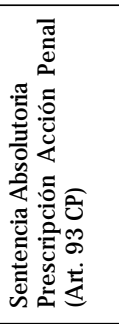 & 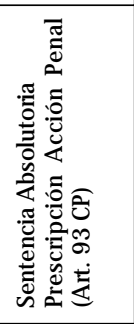 & 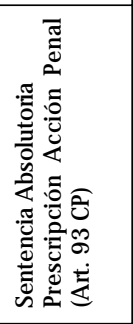 & 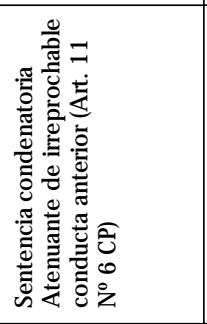 & 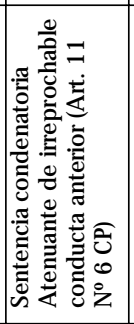 & 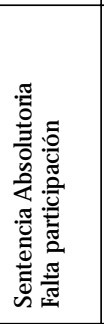 & 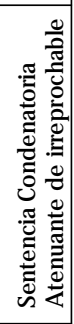 \\
\hline 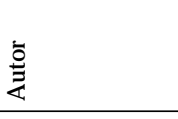 & $\frac{\grave{o}}{\frac{3}{4}}$ & 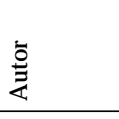 & 高 & 产 & 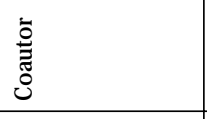 & 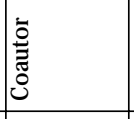 & 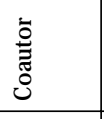 & $\begin{array}{l}\mathbf{2} \\
\text { 妾 }\end{array}$ \\
\hline 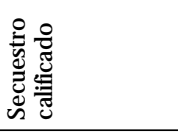 & 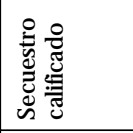 & 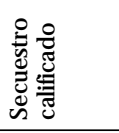 & 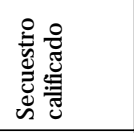 & 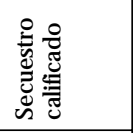 & 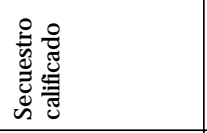 & 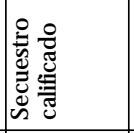 & 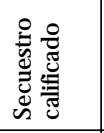 & 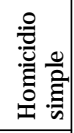 \\
\hline 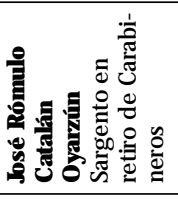 & 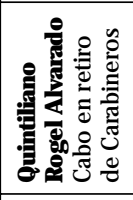 & 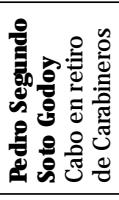 & 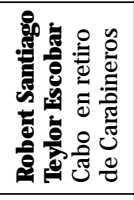 & 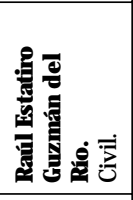 & 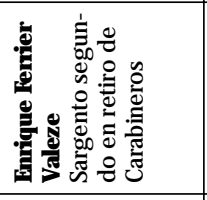 & 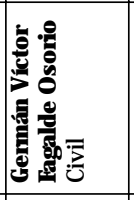 & 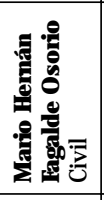 & 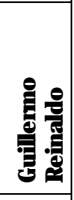 \\
\hline & & & & & $r$ & & & \\
\hline & & & & & 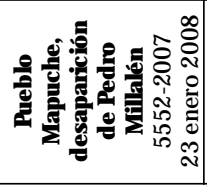 & & & 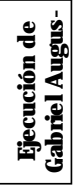 \\
\hline
\end{tabular}




\begin{tabular}{|c|c|c|c|c|c|c|}
\hline 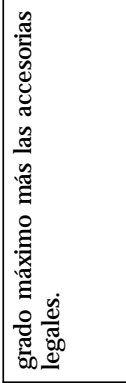 & $\begin{array}{l}\frac{8}{9} \\
\frac{0}{3} \\
\frac{10}{4}\end{array}$ & 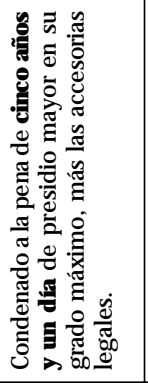 & 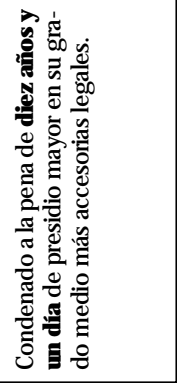 & 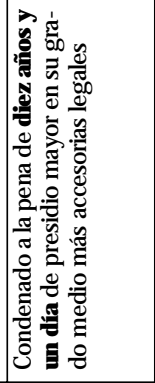 & 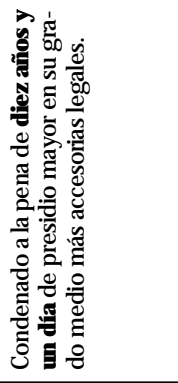 & $\frac{\dot{8}}{\frac{8}{0}}$ \\
\hline \multirow[t]{3}{*}{ 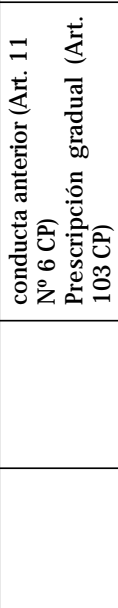 } & 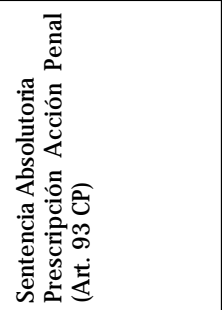 & 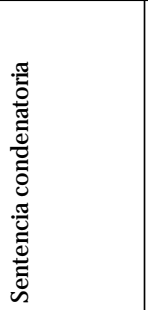 & 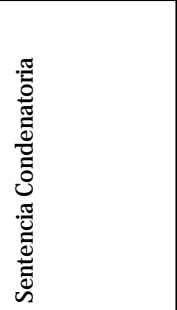 & 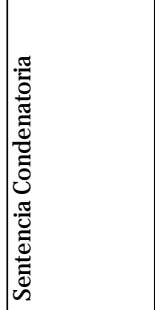 & 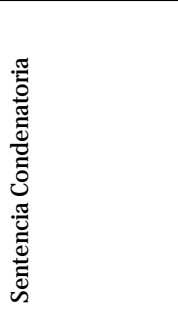 & 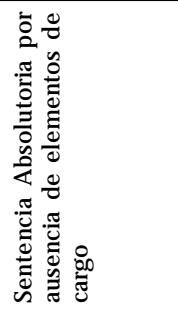 \\
\hline & 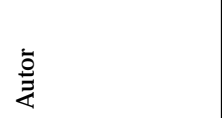 & 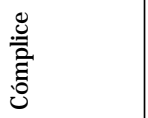 & 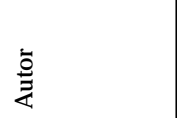 & $\mid \frac{\grave{9}}{\frac{9}{\alpha}}$ & $\frac{\grave{g}}{\frac{3}{\alpha}}$ & 产 \\
\hline & 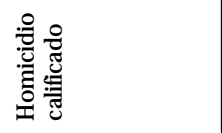 & 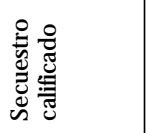 & 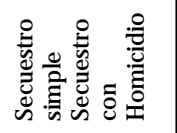 & 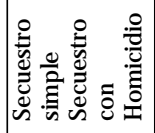 & 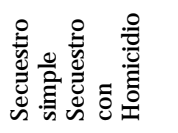 & 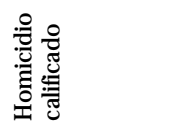 \\
\hline \multirow[t]{2}{*}{ 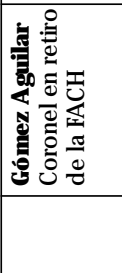 } & 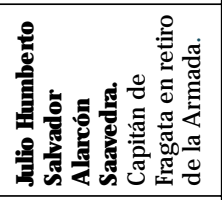 & 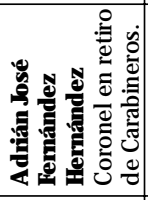 & 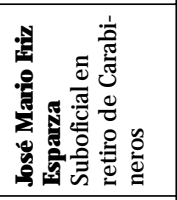 & 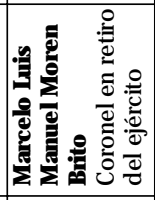 & 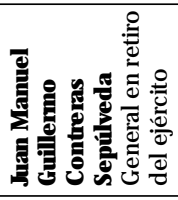 & 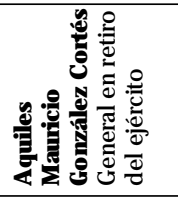 \\
\hline & $r$ & $N$ & $\wedge$ & & & $r$ \\
\hline 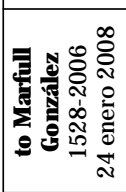 & 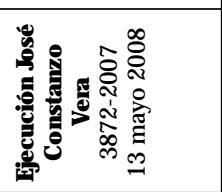 & 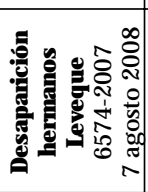 & 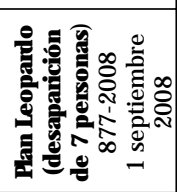 & & & 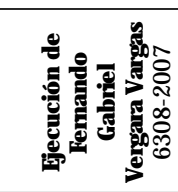 \\
\hline
\end{tabular}




\begin{tabular}{|c|c|c|c|c|c|c|c|}
\hline & & 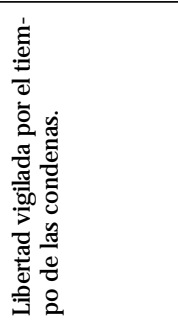 & 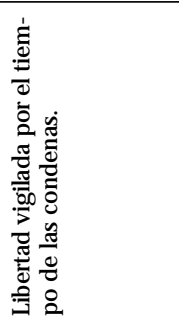 & 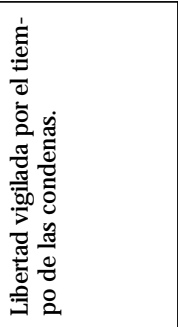 & 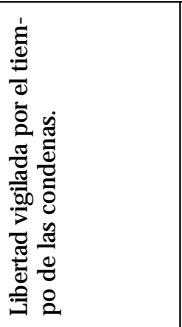 & 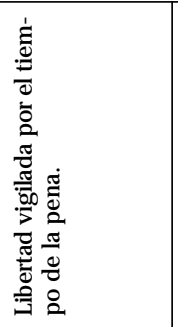 & \\
\hline & $\begin{array}{l}\frac{9}{3} \\
\frac{1}{3} \\
0 \\
\frac{0}{4}\end{array}$ & 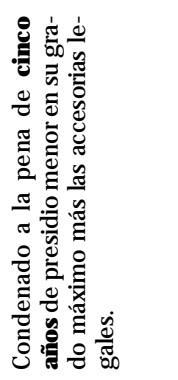 & 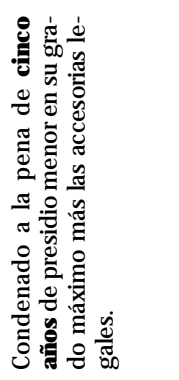 & 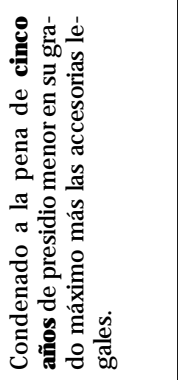 & 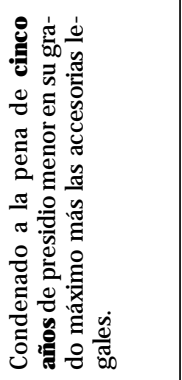 & 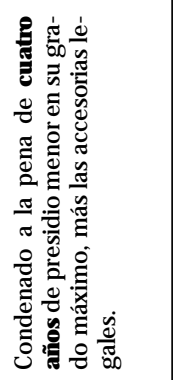 & $\begin{array}{l}\frac{8}{8} \\
\frac{9}{2} \\
0 \\
\frac{0}{4}\end{array}$ \\
\hline & 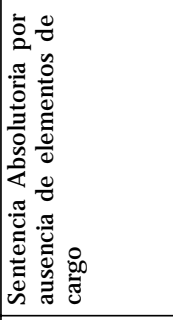 & 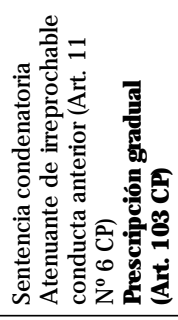 & 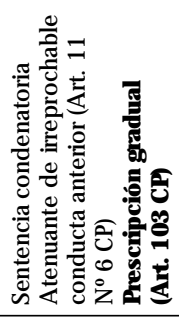 & 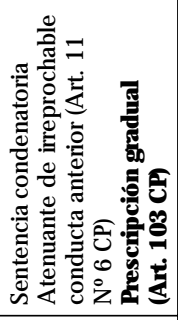 & 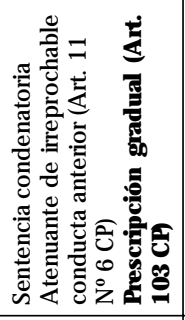 & 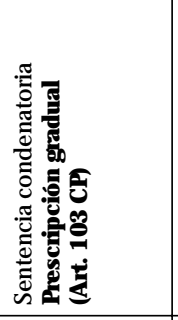 & 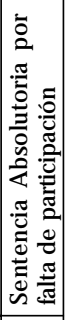 \\
\hline & 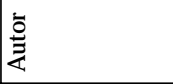 & 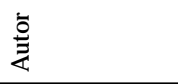 & 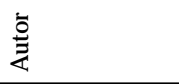 & $\begin{array}{l}\grave{0} \\
\text { ț }\end{array}$ & $\begin{array}{l}\overline{0} \\
\stackrel{3}{4}\end{array}$ & 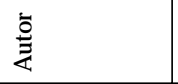 & 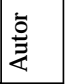 \\
\hline & 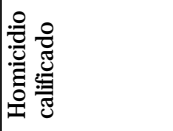 & 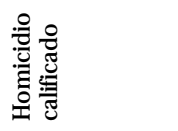 & 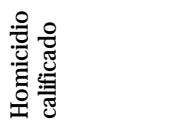 & 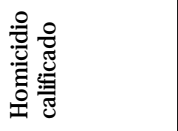 & 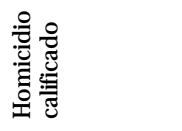 & 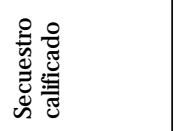 & 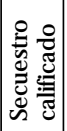 \\
\hline & 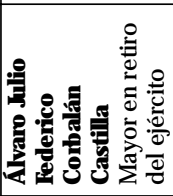 & 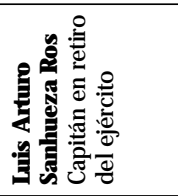 & 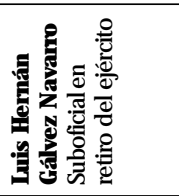 & 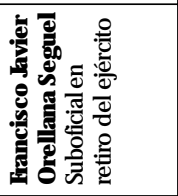 & 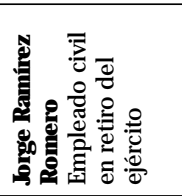 & 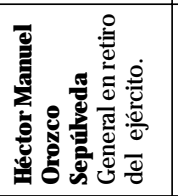 & 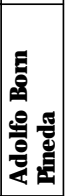 \\
\hline & & & & & & $r$ & \\
\hline 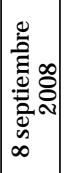 & & & & & & 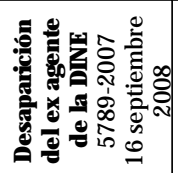 & \\
\hline
\end{tabular}




\begin{tabular}{|c|c|c|c|c|c|c|}
\hline & 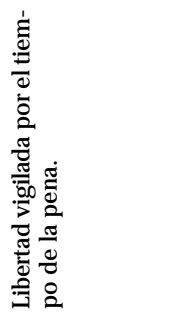 & 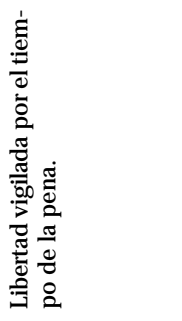 & & & & \\
\hline & 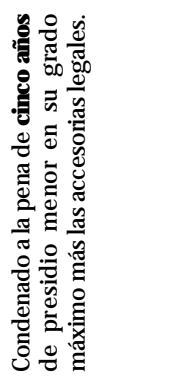 & 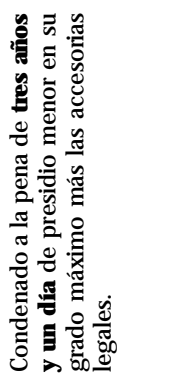 & $\begin{array}{l}\frac{8}{0} \\
\frac{8}{4} \\
\frac{8}{4}\end{array}$ & 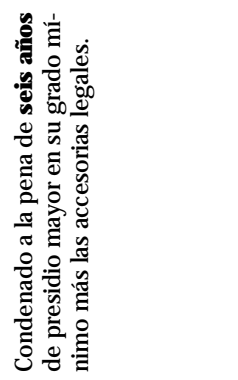 & $\begin{array}{l}\frac{8}{0} \\
\frac{8}{40} \\
\frac{0}{4}\end{array}$ & 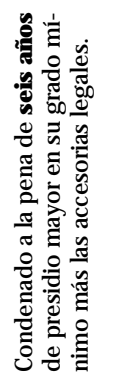 \\
\hline & 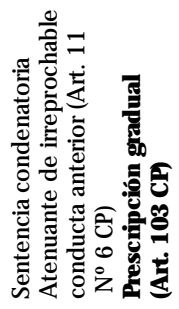 & 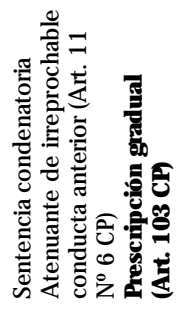 & 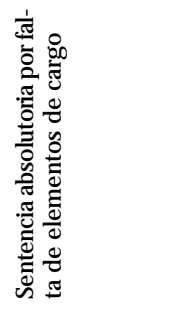 & 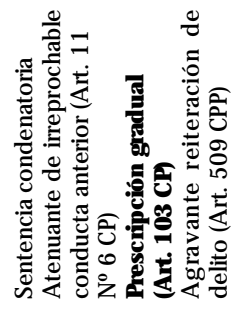 & 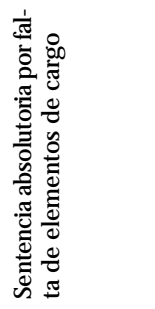 & 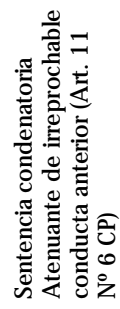 \\
\hline & $\begin{array}{l}\frac{1}{0} \\
\frac{1}{4}\end{array}$ & $\begin{array}{l}\frac{1}{0} \\
\frac{1}{4}\end{array}$ & $\frac{\grave{2}}{3}$ & $\begin{array}{l}\grave{2} \\
\frac{1}{3}\end{array}$ & $\begin{array}{l}\overline{0} \\
\frac{1}{4}\end{array}$ & 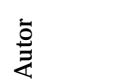 \\
\hline & 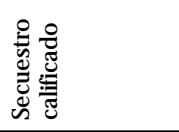 & 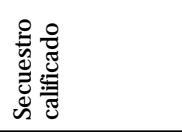 & 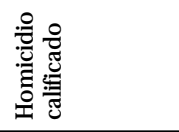 & 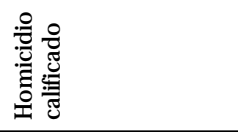 & 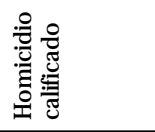 & 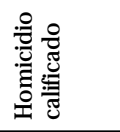 \\
\hline 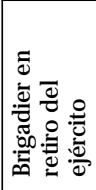 & 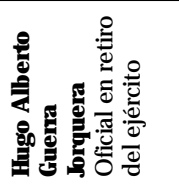 & 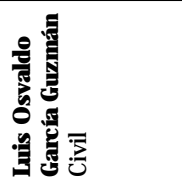 & 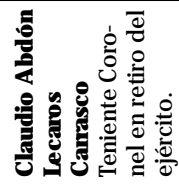 & 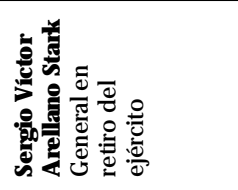 & 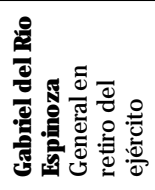 & 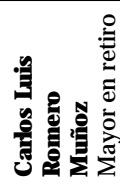 \\
\hline & $\Rightarrow$ & & $\sigma$ & & & \\
\hline & 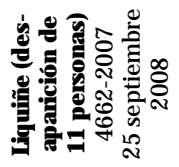 & & 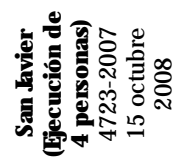 & & & \\
\hline
\end{tabular}




\begin{tabular}{|c|c|c|c|c|}
\hline & 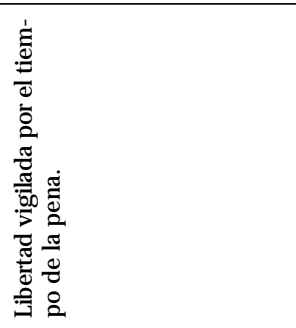 & 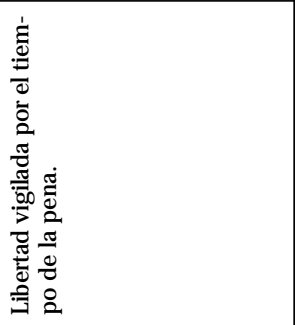 & 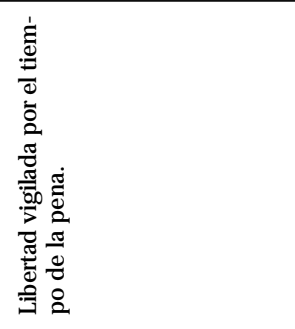 & \\
\hline & 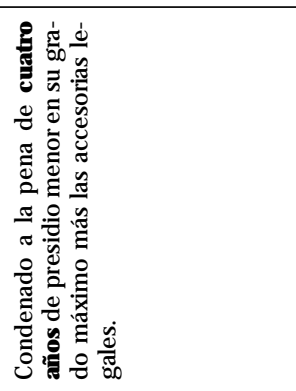 & 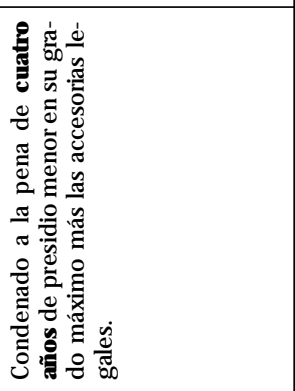 & 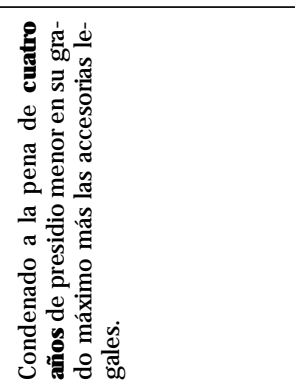 & 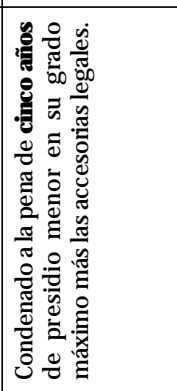 \\
\hline \multirow[t]{3}{*}{ 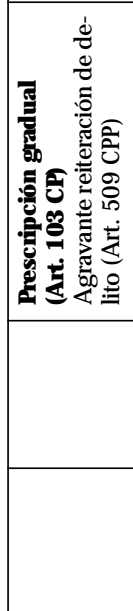 } & 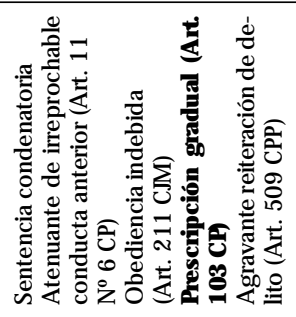 & 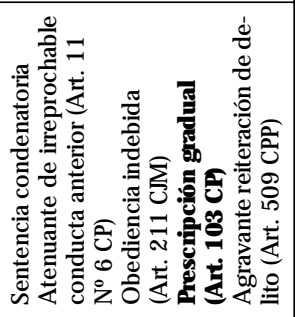 & 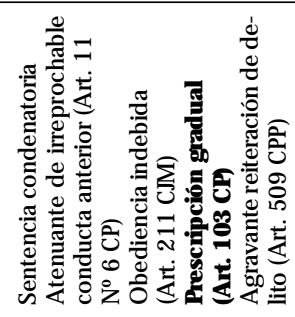 & 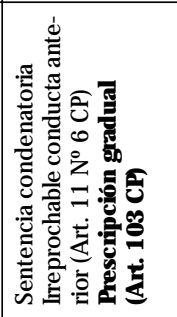 \\
\hline & 产 & 率 & 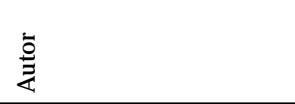 & $\begin{array}{l}\overline{\grave{a}} \\
\text { 总 }\end{array}$ \\
\hline & 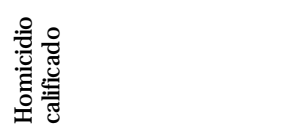 & 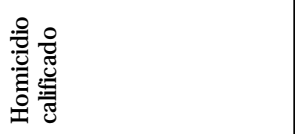 & 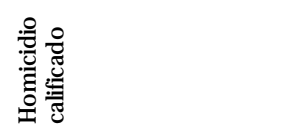 & 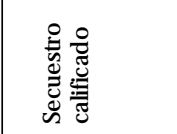 \\
\hline \multirow[t]{3}{*}{ 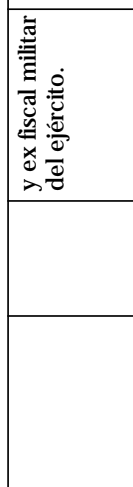 } & 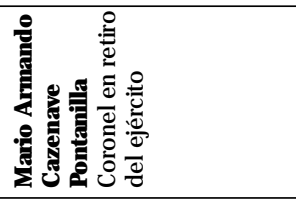 & 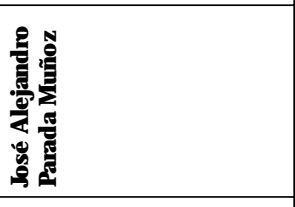 & 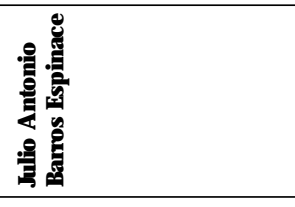 & 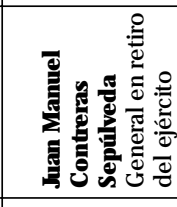 \\
\hline & & & & $r$ \\
\hline & & & & 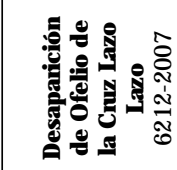 \\
\hline
\end{tabular}




\begin{tabular}{|c|c|c|c|c|c|c|}
\hline & & & 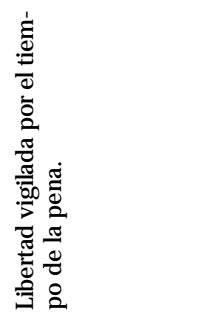 & 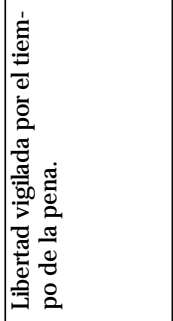 & & 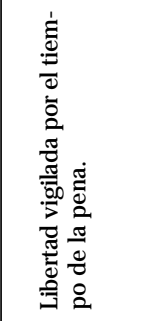 \\
\hline & 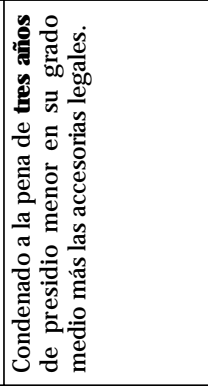 & 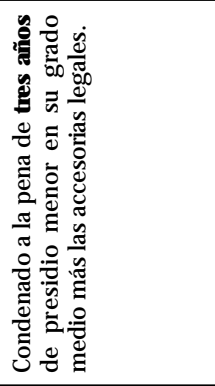 & 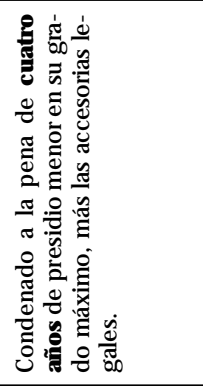 & 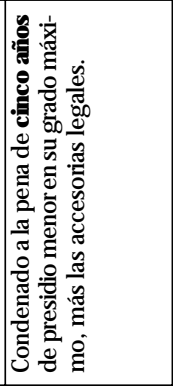 & $\begin{array}{l}\frac{8}{0} \\
\frac{8}{4} \\
\frac{0}{4}\end{array}$ & 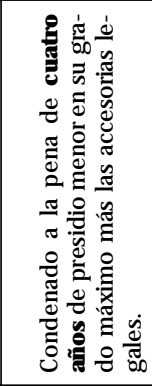 \\
\hline & 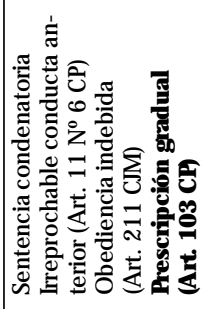 & 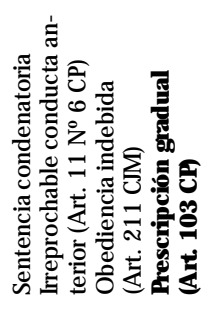 & 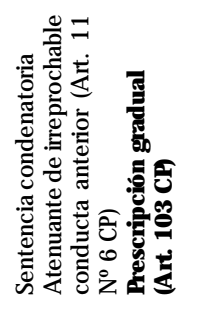 & 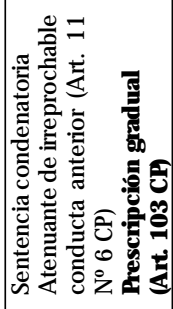 & 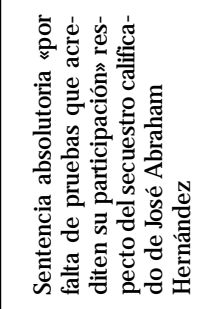 & 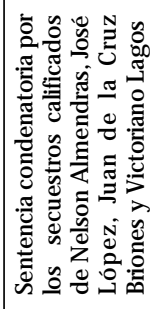 \\
\hline & 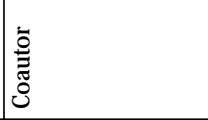 & 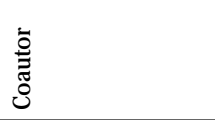 & $\begin{array}{l}\overline{0} \\
\overline{0} \\
\stackrel{0}{0}\end{array}$ & 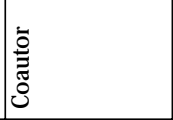 & 产 & 产 \\
\hline & 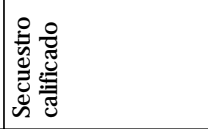 & 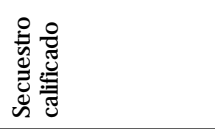 & 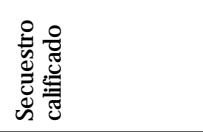 & 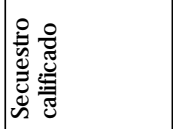 & 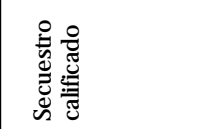 & 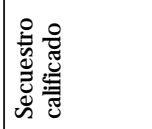 \\
\hline & 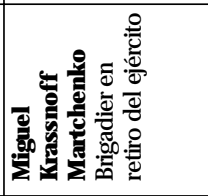 & 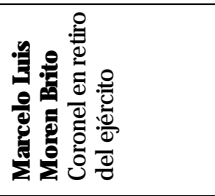 & 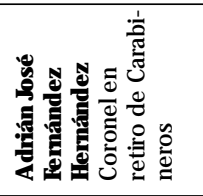 & 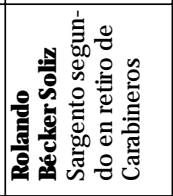 & 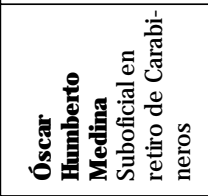 & \\
\hline & & & $r$ & & in & \\
\hline 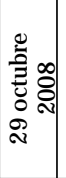 & & & 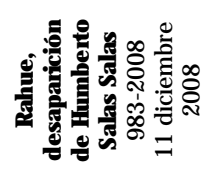 & & 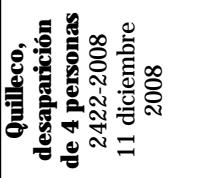 & \\
\hline
\end{tabular}




\begin{tabular}{|c|c|c|c|c|c|}
\hline & & & & & 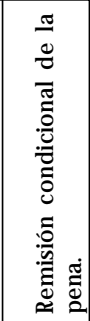 \\
\hline & 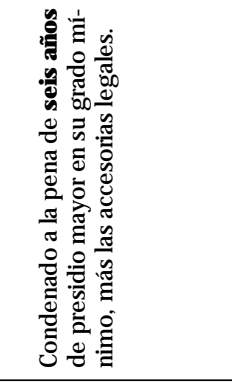 & 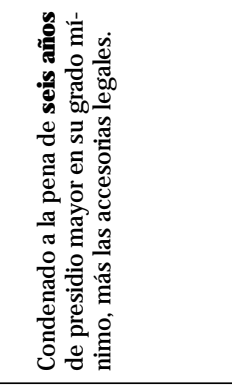 & 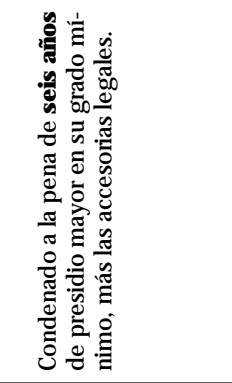 & 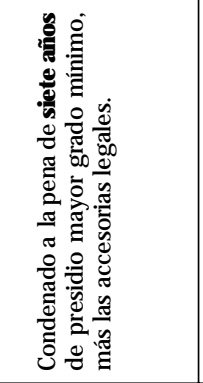 & 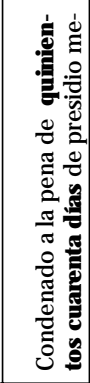 \\
\hline \multirow[t]{6}{*}{ 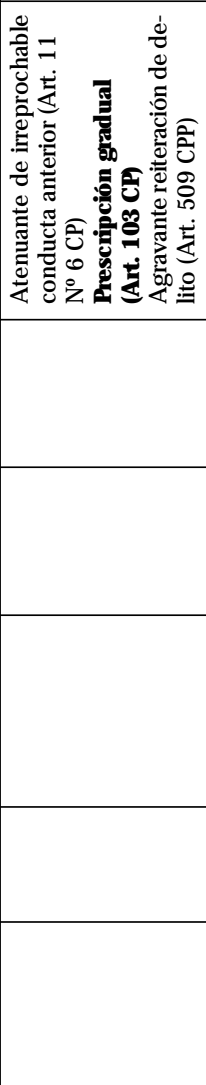 } & 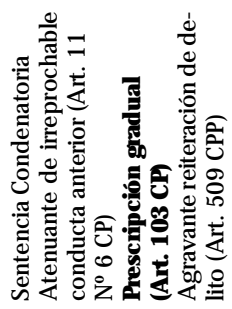 & 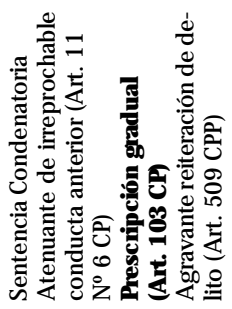 & 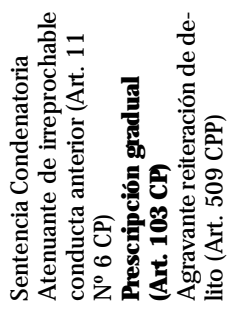 & 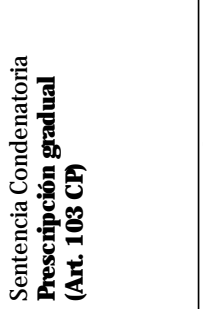 & 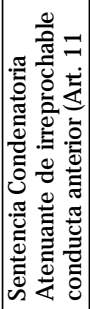 \\
\hline & 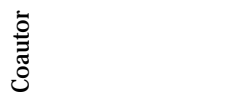 & \begin{tabular}{l} 
के \\
\multirow{3}{0}{} \\
$\stackrel{0}{0}$
\end{tabular} & $\begin{array}{l}\text { ⿳亠口冋口 } \\
\overline{0} \\
0 \\
0\end{array}$ & 产 & $\begin{array}{l}\grave{2} \\
\dot{3} \\
\frac{3}{4}\end{array}$ \\
\hline & 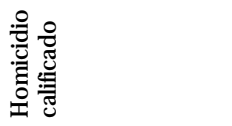 & 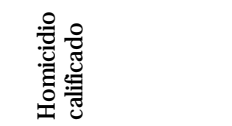 & 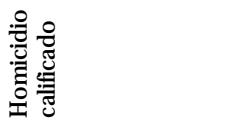 & 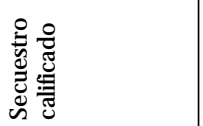 & 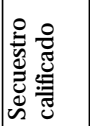 \\
\hline & 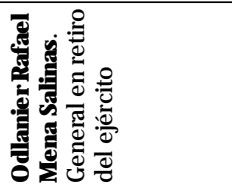 & 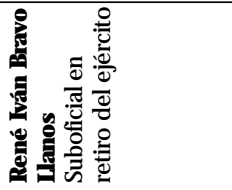 & 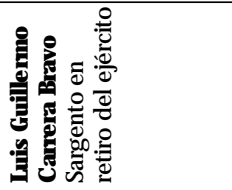 & 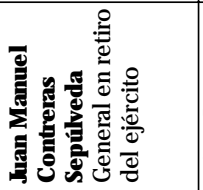 & 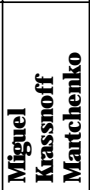 \\
\hline & $m$ & & & $N$ & \\
\hline & 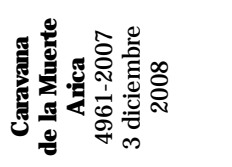 & & & 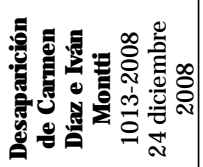 & \\
\hline
\end{tabular}




\begin{tabular}{|c|c|c|c|c|c|c|c|}
\hline & 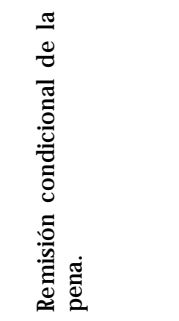 & 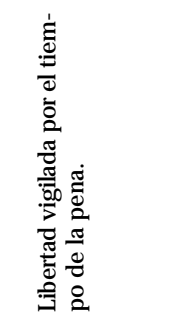 & 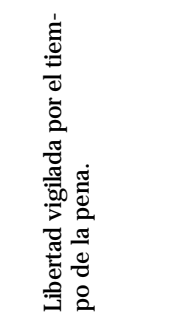 & & & & \\
\hline 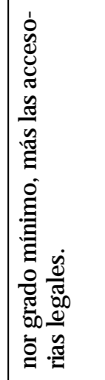 & 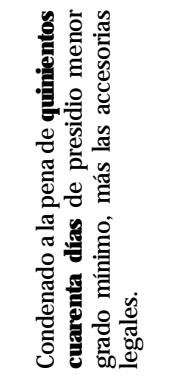 & 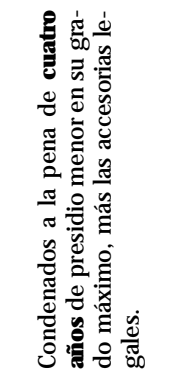 & 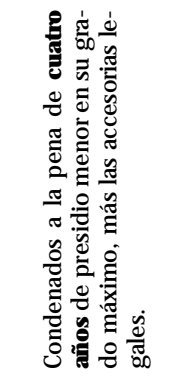 & 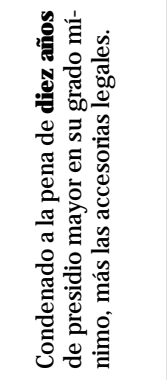 & 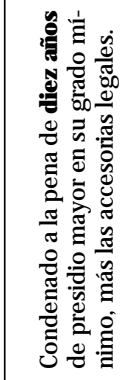 & $\begin{array}{l}\frac{8}{0} \\
\frac{8}{01} \\
\frac{8}{4}\end{array}$ & $\begin{array}{l}\frac{8}{0} \\
\frac{0}{4} \\
\frac{8}{4}\end{array}$ \\
\hline \multirow[t]{3}{*}{ 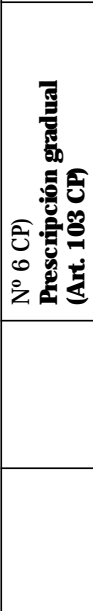 } & 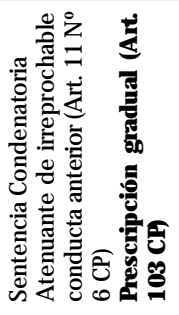 & 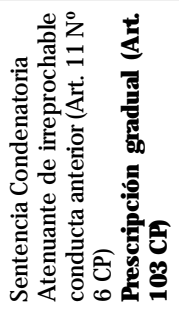 & 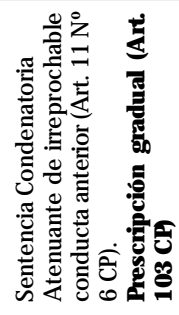 & 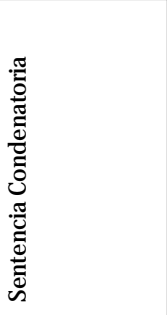 & 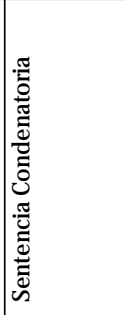 & 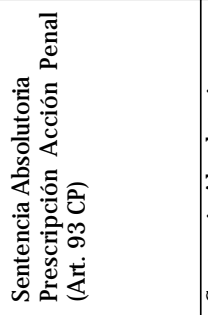 & 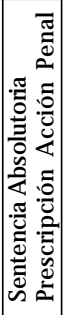 \\
\hline & 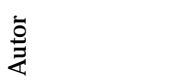 & $\begin{array}{l}\grave{9} \\
\frac{1}{3}\end{array}$ & 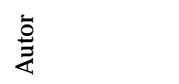 & 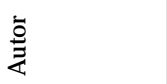 & 产 & 产 & $\begin{array}{l} \\
\frac{9}{3} \\
\frac{3}{4}\end{array}$ \\
\hline & 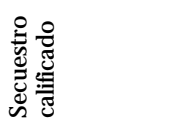 & 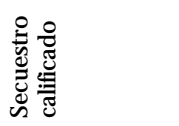 & 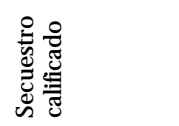 & 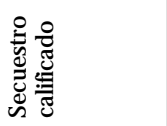 & 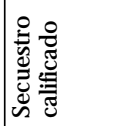 & 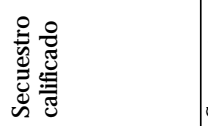 & 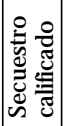 \\
\hline \multirow[t]{3}{*}{ 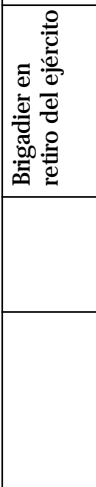 } & 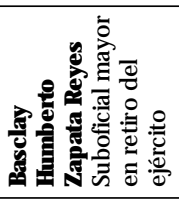 & 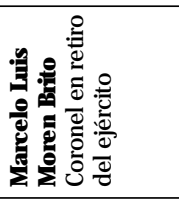 & 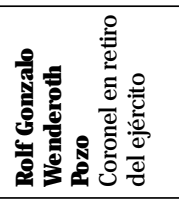 & 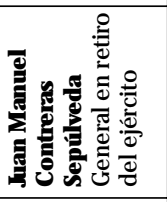 & 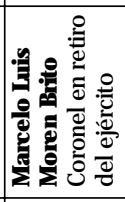 & 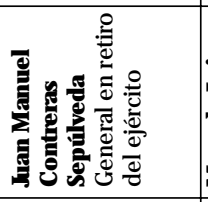 & 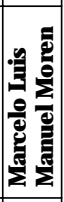 \\
\hline & & & & $N$ & & $r$ & \\
\hline & & & & 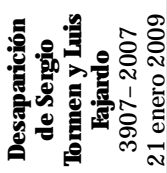 & & 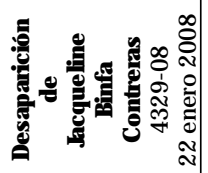 & \\
\hline
\end{tabular}




\begin{tabular}{|c|c|c|c|c|c|c|}
\hline & & & & 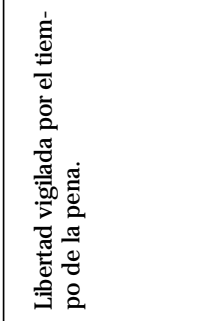 & 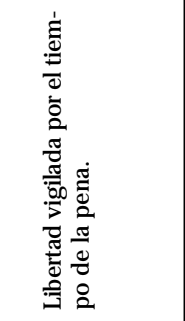 & 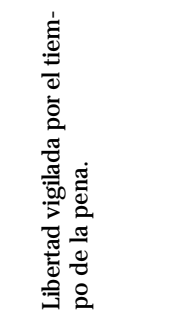 \\
\hline & $\begin{array}{l}\frac{8}{9} \\
\frac{0}{4} \\
\frac{0}{4}\end{array}$ & $\begin{array}{l}\frac{8}{0} \\
\frac{8}{0} \\
\frac{0}{4}\end{array}$ & $\begin{array}{l}\frac{8}{0} \\
\frac{9}{0} \\
\frac{0}{4}\end{array}$ & 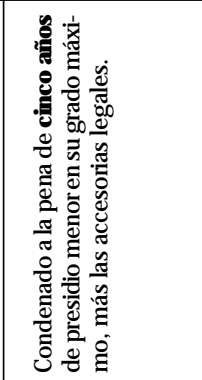 & 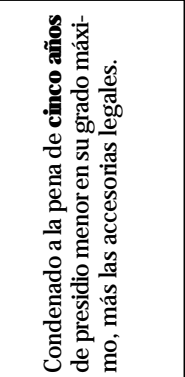 & 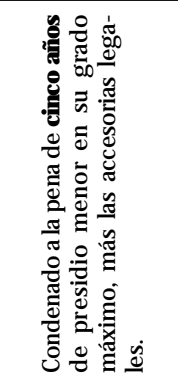 \\
\hline \multirow[t]{3}{*}{$\begin{array}{l}\widehat{\delta} \\
\text { m } \\
\text { ṫ} \\
\text { s }\end{array}$} & 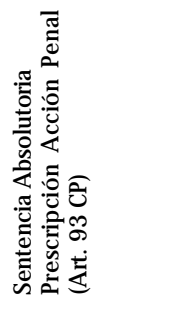 & 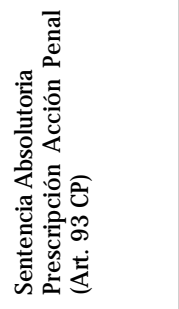 & 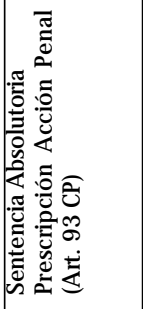 & 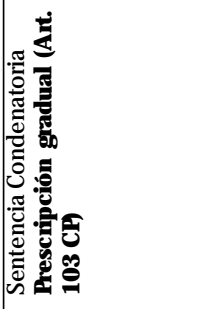 & 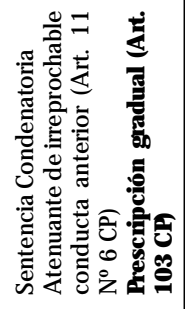 & 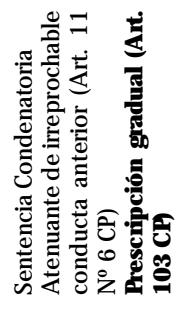 \\
\hline & $\begin{array}{l}\overline{0} \\
\frac{1}{3} \\
\end{array}$ & 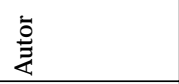 & 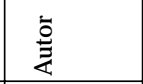 & $\begin{array}{l}\overline{0} \\
\frac{1}{3}\end{array}$ & $\begin{array}{l}\overline{0} \\
\frac{1}{3} \\
\end{array}$ & 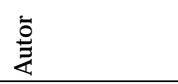 \\
\hline & 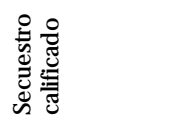 & 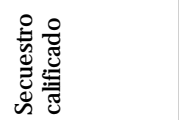 & 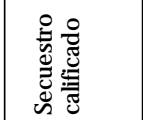 & 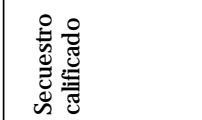 & 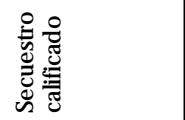 & 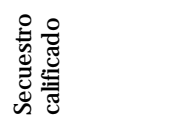 \\
\hline 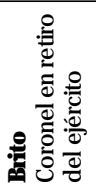 & 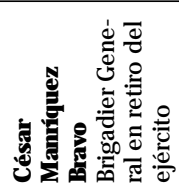 & 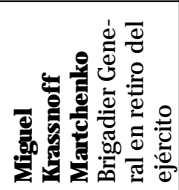 & 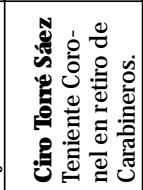 & 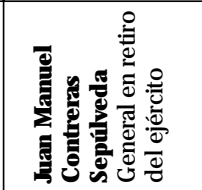 & 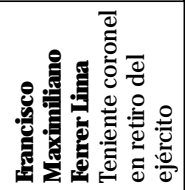 & 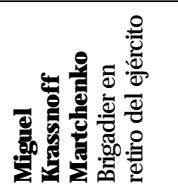 \\
\hline & & & & $r$ & & \\
\hline & & & & 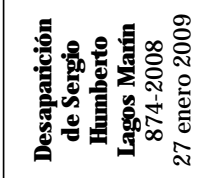 & & \\
\hline
\end{tabular}




\begin{tabular}{|c|c|c|c|c|c|c|}
\hline 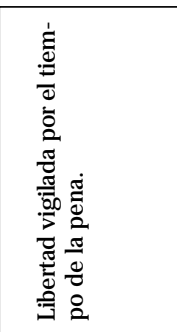 & 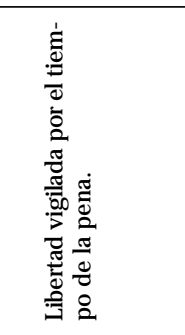 & 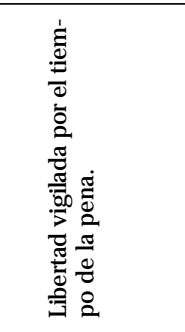 & 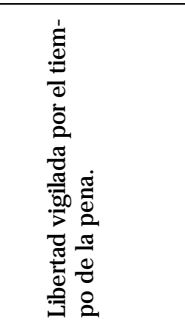 & 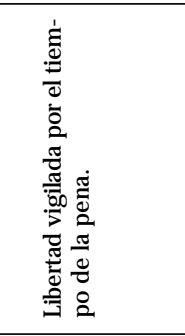 & 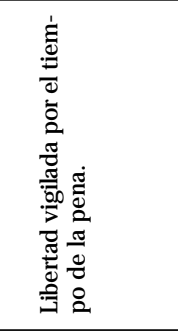 & 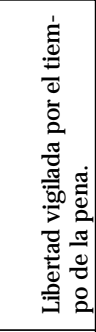 \\
\hline 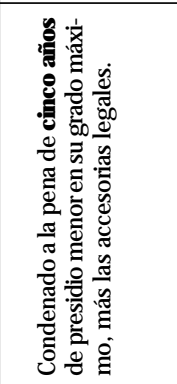 & 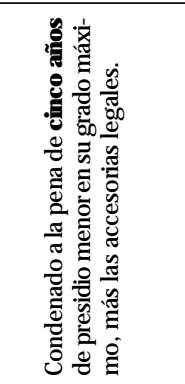 & 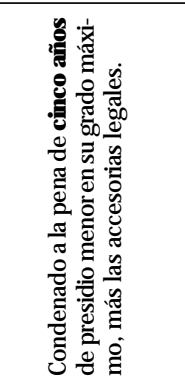 & 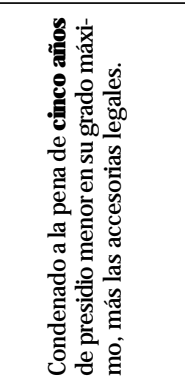 & 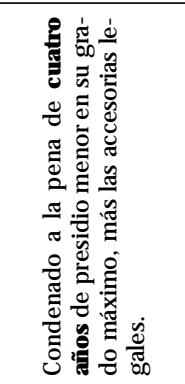 & 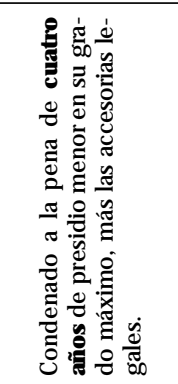 & 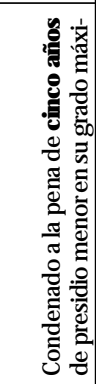 \\
\hline 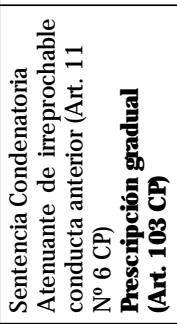 & 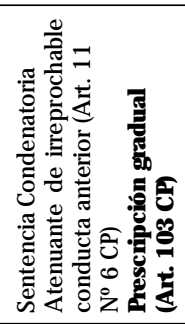 & 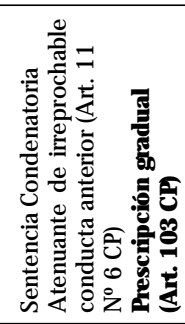 & 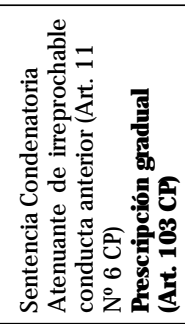 & 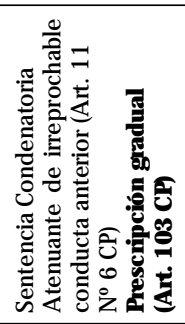 & 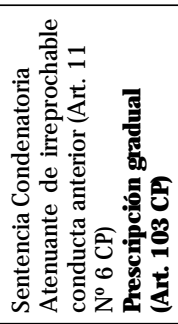 & 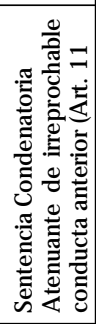 \\
\hline$\frac{\grave{o}}{\frac{3}{\alpha}}$ & $\frac{\grave{2}}{\frac{3}{4}}$ & $\frac{\grave{2}}{\frac{3}{4}}$ & $\frac{\grave{2}}{\frac{3}{4}}$ & $\frac{\grave{o}}{\frac{3}{4}}$ & $\frac{\grave{2}}{\frac{3}{4}}$ & $\frac{\grave{2}}{y_{4}}$ \\
\hline 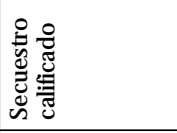 & 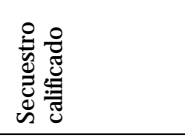 & 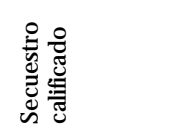 & 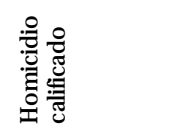 & 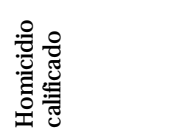 & 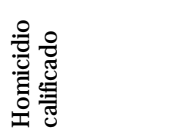 & 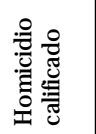 \\
\hline 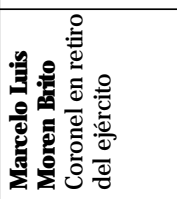 & 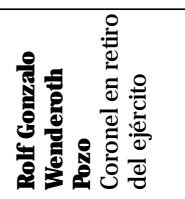 & 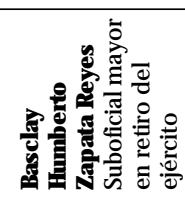 & 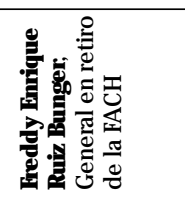 & 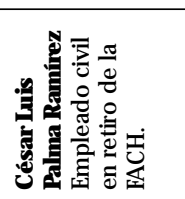 & 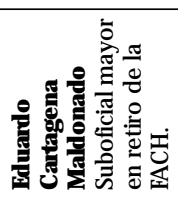 & 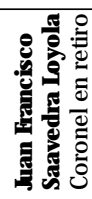 \\
\hline & & & $r$ & & & \\
\hline & & & 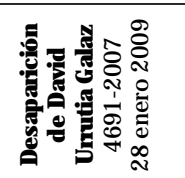 & & & \\
\hline
\end{tabular}




\begin{tabular}{|c|c|c|c|c|}
\hline & & 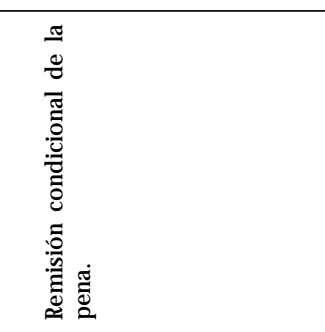 & 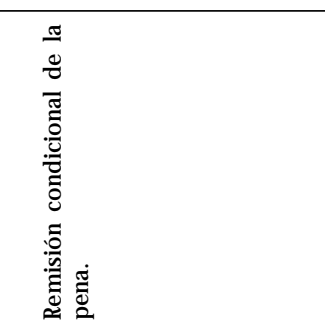 & 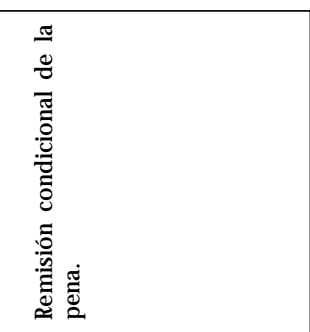 \\
\hline 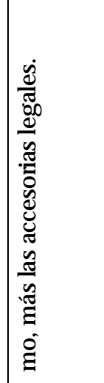 & 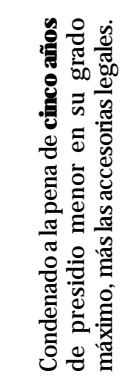 & 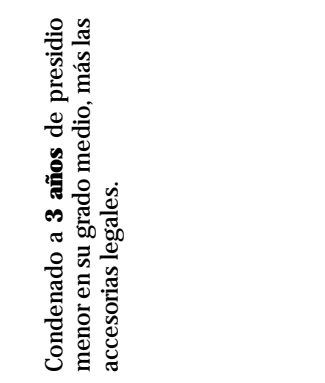 & 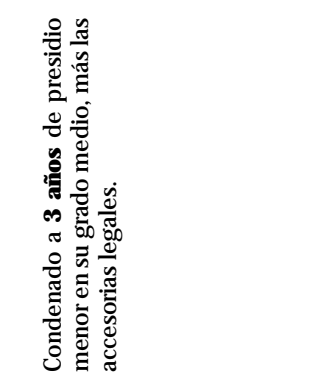 & 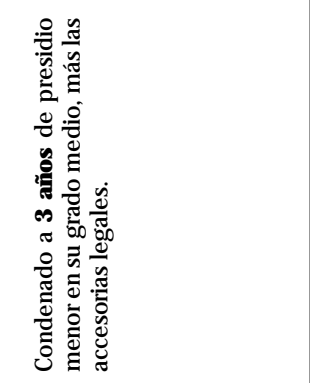 \\
\hline \multirow[t]{3}{*}{ 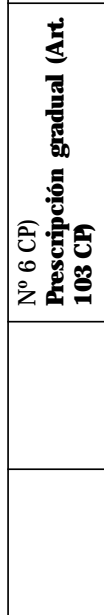 } & 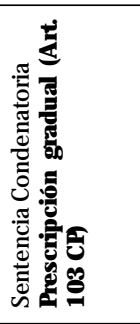 & 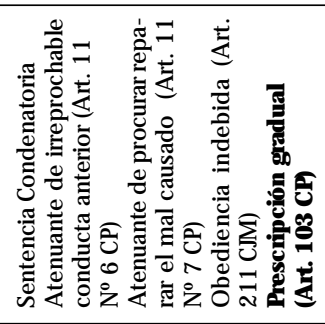 & 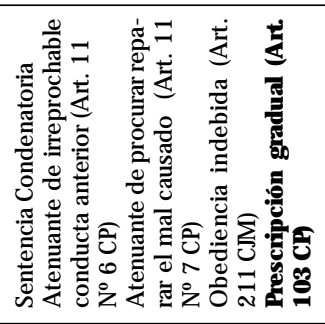 & 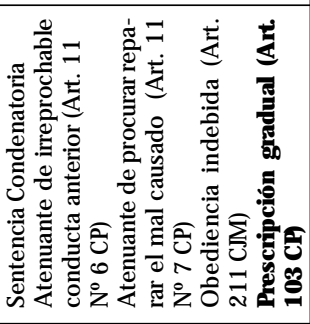 \\
\hline & $\frac{\grave{o}}{\frac{\pi}{4}}$ & $\begin{array}{l}\text { ò̀ } \\
\text { 总 }\end{array}$ & 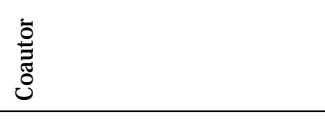 & 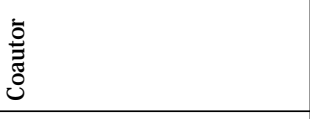 \\
\hline & 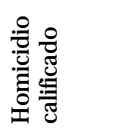 & 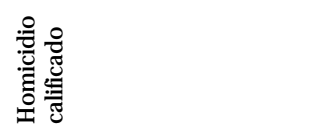 & 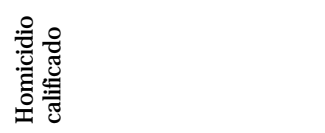 & 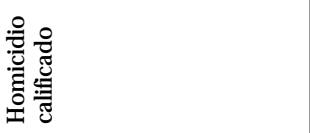 \\
\hline \multirow[t]{3}{*}{ 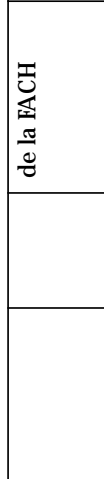 } & 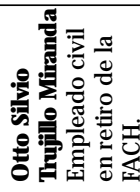 & 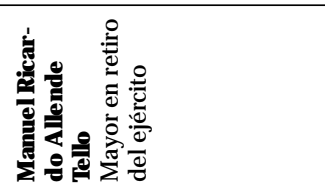 & 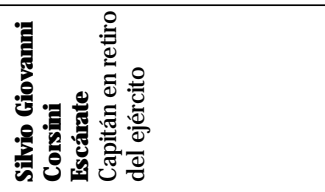 & 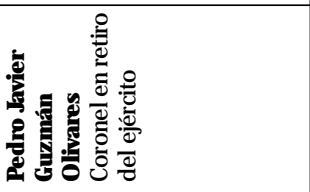 \\
\hline & & $H$ & & \\
\hline & & 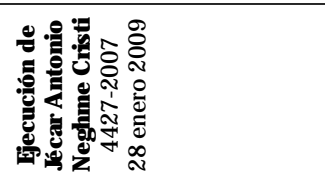 & & \\
\hline
\end{tabular}


Karinna Fernández Neira • Pietro Sferrazza Taibi

\begin{tabular}{|c|c|c|c|c|}
\hline 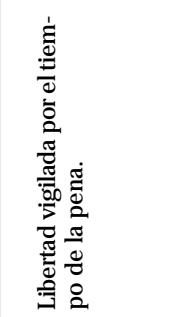 & 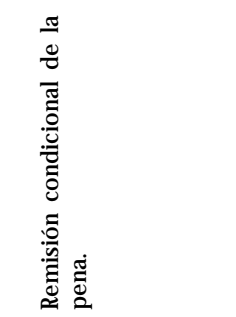 & 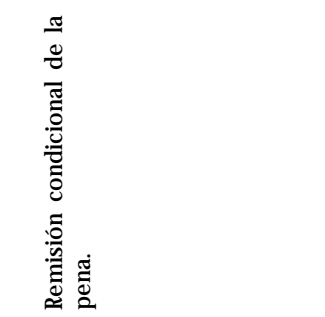 & & \\
\hline 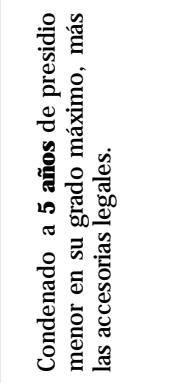 & 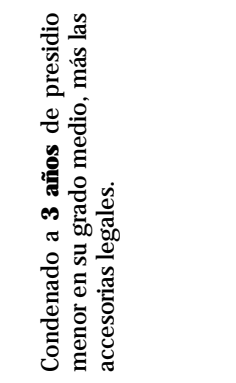 & 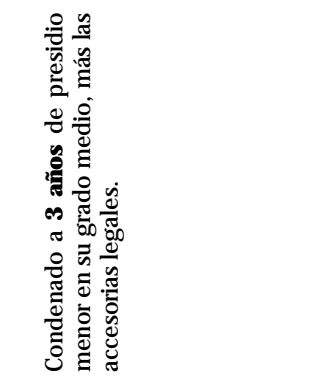 & $\begin{array}{l}\frac{8}{0} \\
\frac{0}{00} \\
\frac{0}{4}\end{array}$ & $\begin{array}{l}\frac{8}{2} \\
\frac{0}{0} \\
\frac{0}{4}\end{array}$ \\
\hline 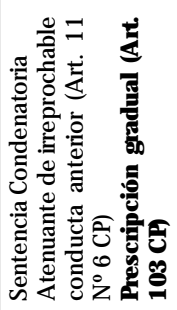 & 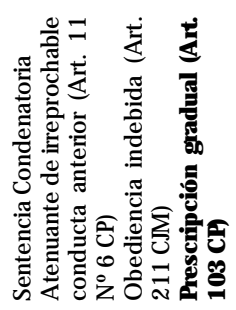 & 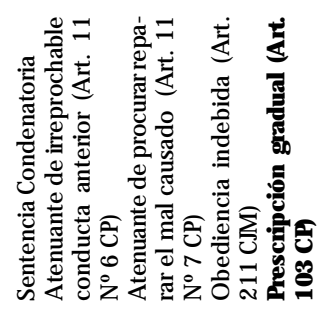 & 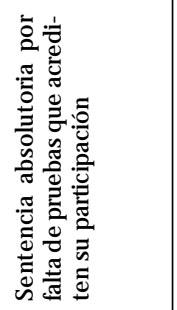 & 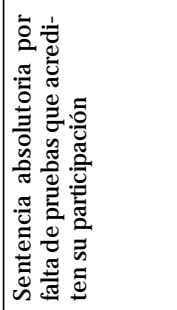 \\
\hline 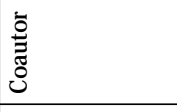 & 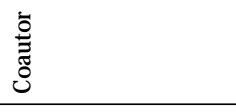 & 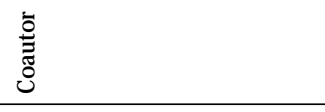 & 高 & $\begin{array}{l}\grave{2} \\
\frac{1}{4}\end{array}$ \\
\hline 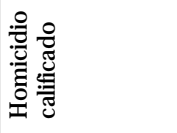 & 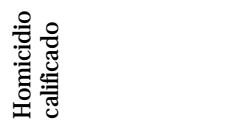 & 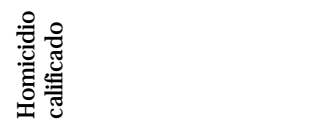 & 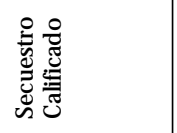 & 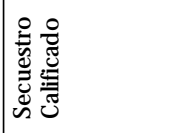 \\
\hline \multirow[t]{3}{*}{ 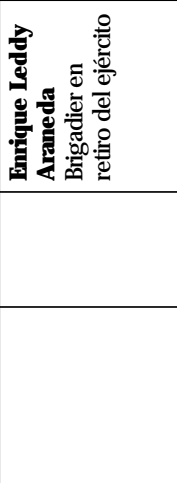 } & 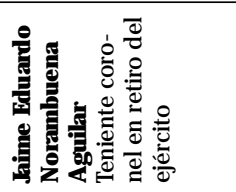 & 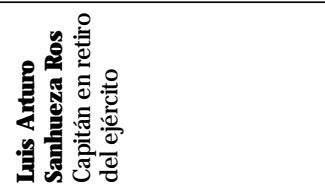 & 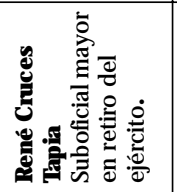 & 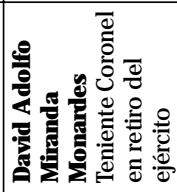 \\
\hline & & & $r$ & \\
\hline & & & 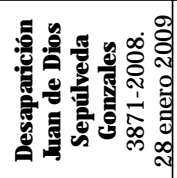 & \\
\hline
\end{tabular}

